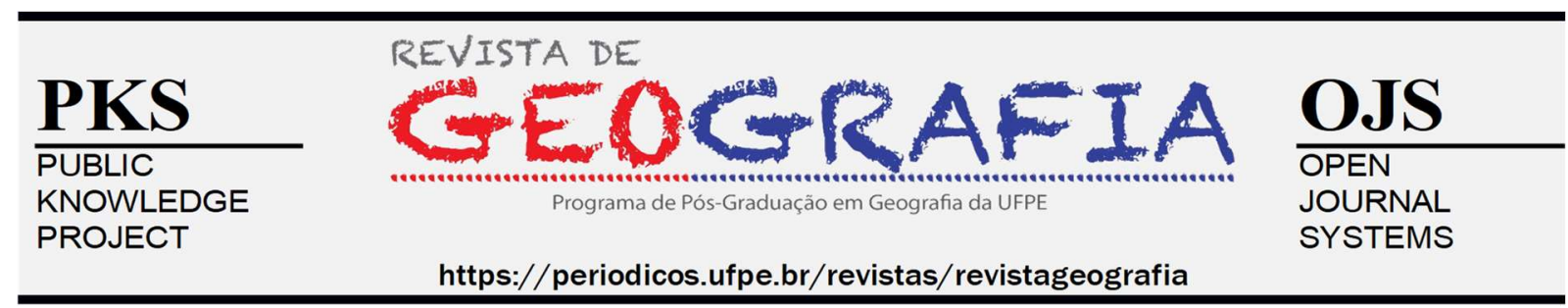

\title{
QUALIDADE DAS ÁGUAS SUBTERRÂNEAS NA BACIA ENDORREICA DO TABULEIRO DO MARTINS, MACEIÓ-AL
}

\author{
Robson Bezerra de Lima ${ }^{1}$, José Vicente Ferreira Neto ${ }^{2}$
}

\begin{abstract}
${ }^{1}$ Mestre em Geografia - UFAL; Graduação em Geografia - UFAL; E-mail: robsongeografia@outlook.com; ORCID: https://orcid.org/0000-0003-0232-2567

2 Doutorado em Geociências e Meio Ambiente - UNESP; Graduação em Eng. Civil - UFAL; E-mail: jvferreiraneto@globo.com; ORCID: https://orcid.org/0000-0001-5664-9114
\end{abstract}

Artigo recebido em 04/07/2020 e aceito em 17/11/2020

\section{RESUMO}

A água é um recurso natural limitado, provavelmente o único recurso natural associado com todos os aspectos da civilização humana, desde o desenvolvimento agrícola e industrial aos valores culturais e religiosos arraigados na sociedade. É essencial à vida, seja como componente bioquímico de seres vivos, como meio de vida de várias espécies vegetais e animais, como elemento representativo de valores sociais e culturais e até como fator de produção de vários bens de consumo final e intermediário. Esta pesquisa traz, como temática, o estudo da qualidade das águas subterrâneas da bacia endorreica do Tabuleiro do Martins, Maceió/AL, localizada no domínio dos Tabuleiros Costeiros de Maceió, na bacia sedimentar Alagoas, onde essas águas são intensivamente exploradas para consumo humano e industrial. Trata-se de um sistema de drenagem interna, onde as águas superficiais se acumulam nas depressões do terreno natural, de onde evaporam ou infiltram no solo. A região possui clima tropical, subúmido seco, com baixa amplitude térmica e precipitações anuais em torno de $1480 \mathrm{~mm}$, referente ao período 1913 a 1983. A recarga dos sistemas aquíferos se dá principalmente pela infiltração do excedente de águas pluviais, estimada em $400 \mathrm{~mm}$ anuais. Das unidades litoestratigráficas na região, são exploradas as formações Barreiras, Marituba e Poção, isoladamente ou em conjunto, quando formam um só sistema aquífero. Dentre as atividades potencialmente poluidoras identificadas na região, destacam-se: sistema de esgotamento sanitário, constituído por fossas sépticas e sumidouros; efluentes líquidos industriais na área do Polo Multissetorial Governador Luiz Cavalcante; postos de combustíveis; e o sistema de drenagem superficial da região, constituído de lagoas para amortecimento de cheias que são também utilizadas como corpos receptores de efluentes domiciliares e industriais. Foi adotado o método hipotético dedutivo para a avaliação da qualidade das águas subterrâneas locais captadas por poços tubulares da Companhia de Saneamento de Alagoas, inicialmente através da análise estatística dos parâmetros físico-químicos determinados pela CASAL nos anos de 2008 e 2018, visando também o estudo comparativo dos dados disponíveis nesse período. Foi avaliada a variabilidade espacial dos parâmetros físicoquímicos das águas subterrâneas, visando identificar áreas sujeitas à contaminação, principalmente em regiões que possuem relevância econômica e ambiental para a sociedade. Também foi identificado o grau de vulnerabilidade natural das águas subterrâneas da bacia endorreica do Tabuleiro do Martins, através do modelo GOD, índice de vulnerabilidade baseado na litologia, na profundidade até o lençol freático e no grau de confinamento da água subterrânea. Por fim, a pesquisa identificou áreas na bacia endorreica do Tabuleiro do Martins onde já há indícios de poluição ou degradação das águas subterrâneas comparando com o grau de vulnerabilidade natural correspondente.

Palavras-chave: Poluição de águas subterrâneas; Geoestatística; Vulnerabilidade de aquíferos. 


\title{
GROUNDWATER QUALITY IN THE ENDORREIC BASIN TABULEIRO DO MARTINS, MACEIÓ-AL
}

\begin{abstract}
Water is a limited natural resource, probably the only natural resource that has to do with all aspects of human civilization, from agricultural and industrial development to cultural and religious values rooted in society. It is essential to life, whether as a biochemical component of living things, as a livelihood of various plant and animal species, as a representative element of social and cultural values, and even as a factor of production of various final and intermediate consumer goods. This research brings, as its theme, the study of the groundwater quality of the endorheic basin of Tabuleiro do Martins, Maceió / AL, located in the Coastal Tablelands of Maceió domain, in the Alagoas sedimentary basin, where these waters are intensively exploited for human consumption. industrial. It is an internal drainage system where surface water accumulates in the depressions of the natural terrain, from which it evaporates or infiltrates the soil. The region has a tropical climate, dry humid, with low thermal amplitude and annual precipitation around $1480 \mathrm{~mm}$. The recharge of aquifer systems is mainly due to the infiltration of surplus rainwater, estimated at $400 \mathrm{~mm}$ per year. From the lithostratigraphic units, the Barreiras, Marituba and Poção formations are explored, alone or together, when they form a single aquifer system. Among the potentially polluting activities identified in the region, the following stand out: sanitary sewage system, consisting of septic tanks and sinks; industrial liquid effluents in the area of the Governador Luiz Cavalcante Multisectoral Complex; gas stations; and the region's surface drainage system, consisting of flood damping lagoons that are also used as household and industrial wastewater receiving bodies. The hypothetical deductive method was adopted to evaluate the quality of local groundwater captured by tubular wells of the Alagoas Sanitation Company, initially through the statistical analysis of the physical-chemical parameters determined by CASAL in 2008 and 2018, aiming at also the comparative study of the data available in this period. The spatial variability of groundwater physicochemical parameters was evaluated in order to identify areas subject to contamination, especially in regions that have economic and environmental relevance to society. It was also identified the degree of natural vulnerability of the groundwater of the endorheic basin of Tabuleiro do Martins, through the GOD model, vulnerability index based on lithology, depth to the water table and the degree of groundwater confinement. Finally, the research identified areas in the endorheic basin of Tabuleiro do Martins where there is already evidence of groundwater pollution or degradation compared with the corresponding degree of natural vulnerability.
\end{abstract}

Keywords: Groundwater pollution; Geostatistics; Aquifer vulnerability.

\section{INTRODUÇÃO}

A água constitui um elemento essencial para a manutenção da vida no planeta e, embora ocupe 3/4 da superfície da Terra, apenas 0,8\% está disponível sob a forma de água doce e não se tem conhecimento de quanto dessa fração encontra-se contaminada (CETESB, 1996).

Segundo alguns especialistas, a crise da água no século XXI é muito mais de gerenciamento do que uma crise real de escassez e estresse (ROGERS, 2006). Entretanto, para outros especialistas, é resultado de um conjunto de problemas ambientais agravados com outros problemas relacionados à economia e ao desenvolvimento social (GLEICK, 2000).

Para Somlyody e Varis (2006), o agravamento e a complexidade da crise da água decorrem de problemas reais de disponibilidade e aumento da demanda, e de um processo de gestão ainda setorial e de resposta a crises e problemas sem atitude preditiva e abordagem sistêmica. 
Tundisi e Matsumura-Tundisi (2008) ressaltam a necessidade de uma abordagem sistêmica, integrada e preditiva na gestão das águas com uma descentralização para a bacia hidrográfica. Segundo esses autores, uma base de dados consolidada e transformada em instrumento de gestão pode ser uma das formas mais eficazes de enfrentar o problema de escassez de água, estresse de água e deterioração da qualidade.

Nas últimas décadas, a preocupação de toda sociedade com a disponibilidade e qualidade da água decorre do fato de que, por mais abundante que pareça este recurso, não é rara também sua escassez, ora pela ocorrência de períodos prolongados de seca, ora pela alta carga poluidora a que é submetida (ESPÍNDULA, 2004).

A urbanização tem contribuído para a degradação da qualidade da água, em virtude do aumento da variedade e quantidade de poluentes transportados pelo deflúvio superficial. Esses poluentes podem prejudicar todos os seres vivos, contaminando fontes de água potável.

A água subterrânea é a parcela que se encontra no subsolo da superfície terrestre, preenchendo os espaços vazios existentes entre os grãos do solo, rochas e fissuras, e está disponível em todas as regiões da Terra, constituindo importante recurso natural (TUNDISI, 2003).

As estratégias de preservação das águas subterrâneas devem englobar: controle e fiscalização na captação e concessão de outorga, minimização de contaminação físico-química, e evitar, ao máximo, as perdas de água.

O presente estudo foi desenvolvido na região norte do município de Maceió, Alagoas, em uma bacia endorreica que envolve áreas localizadas no domínio dos Tabuleiros Costeiros de Maceió, com formação Barreiras, pertencente à bacia sedimentar Alagoas, onde as águas subterrâneas são intensivamente exploradas para consumo humano e industrial.

Segundo Morais (2001) e Morais et al. (2006), a formação Barreiras, apresenta predomínio de depósitos de arenitos maciços ou com estratificação cruzada acanalada, intercalados a lamitos argilosos e arenosos, com poucas camadas conglomeráticas.

Nesse contexto, esta pesquisa, cuja hipótese norteadora está relacionada diretamente a ação antrópica, teve por objetivo avaliar o grau de contaminação das águas subterrâneas e vulnerabilidade na bacia endorreica do Tabuleiro do Martins na cidade de Maceió, com dados obtidos junto a Companhia de Saneamento de Alagoas (CASAL) nos anos de 2008 e 2018. 


\section{METODOLOGIA}

Esta pesquisa possui natureza quantitativa. Utiliza o método hipotético dedutivo com o objetivo de analisar o grau de contaminantes onde a ação antrópica pode comprometer a qualidade das águas subterrâneas da bacia endorreica do Tabuleiro do Martins (Figura 1), localizada na porção noroeste da cidade de Maceió, capital do Estado de Alagoas, e engloba totalmente o bairro Cidade Universitária e, parcialmente, áreas dos bairros Antares, Benedito Bentes, Clima Bom, Santa Lúcia, Santos Dumont e Tabuleiro do Martins, definida pela Lei municipal 4.952, de 06/01/2000.

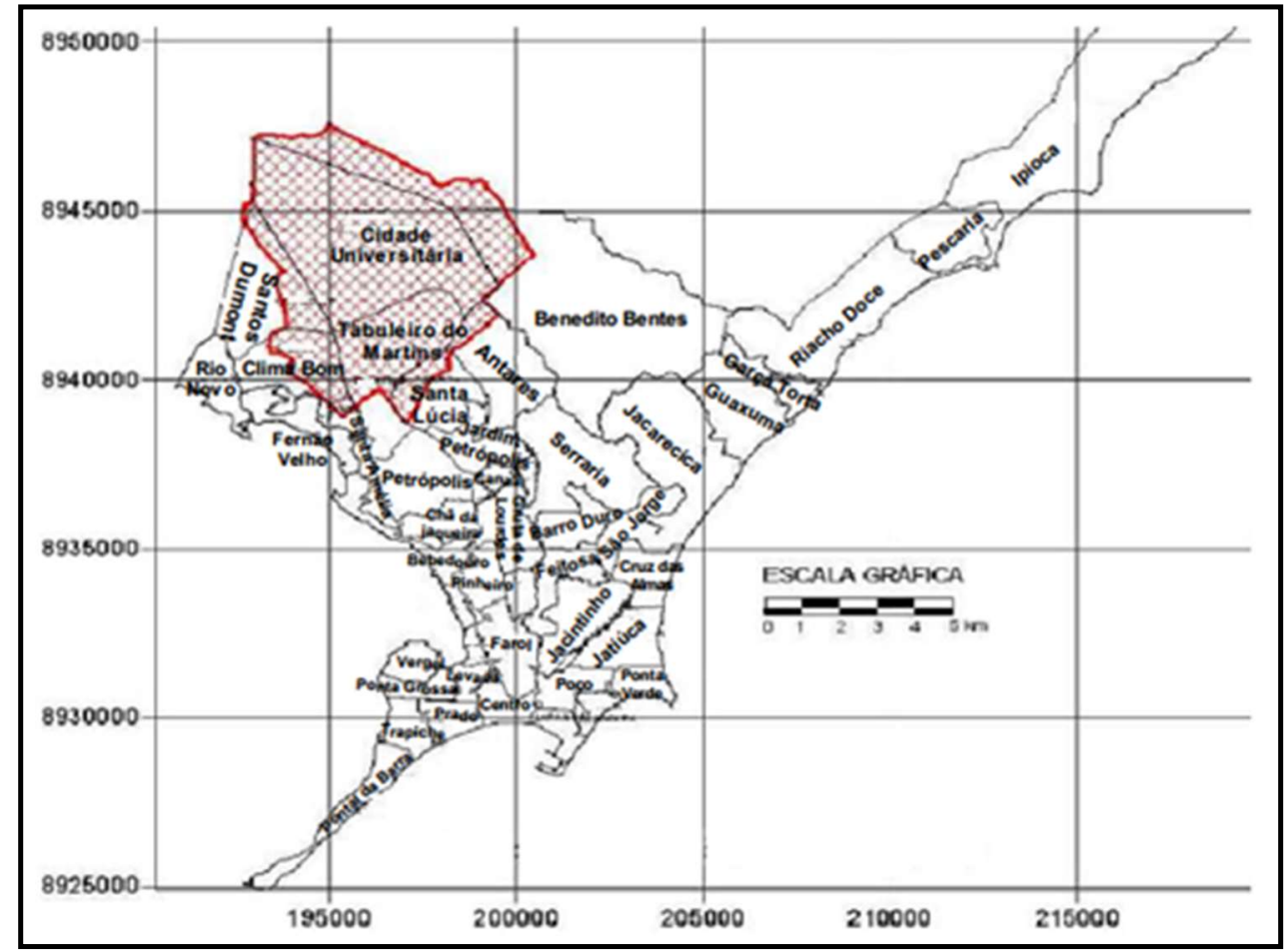

Figura 1. Bacia endorreica do Tabuleiro do Martins

Fonte: adaptado de FERREIRA NETO, 2005 apud SOUZA, 2006

Os dados coletados foram tabulados para execução do cálculo das estatísticas descritivas e da elaboração dos gráficos histograma e bloxpot para análise do comportamento dos diversos parâmetros físicos e químicos da água, permitindo classificar as águas analisadas conforme a legislação. A estatística descritiva constou da determinação dos seguintes parâmetros: mínimo, máximo, média, mediana, variância, desvio padrão, assimetria e curtose.

Os dados físico-químicos, fisiográficos e antrópicos foram quantificados, ou seja, foram caracterizados através dos parâmetros estabelecidos pelos órgãos reguladores. Conforme dados disponíveis, foram selecionados e analisados um total de 27 poços para o ano de 2008 e 19 poços para o ano de 2018 na área de estudo. 
Para a determinação do índice de vulnerabilidade natural do aquífero foi utilizado o método simplificado GOD, referência às iniciais em inglês dos parâmetros utilizados: grau de confinamento da água subterrânea (Groundwater), ocorrência de estratos de cobertura (Overall) e distância até o lençol freático ou teto do aquífero confinado (Depth) (FOSTER et al.,1987; FOSTER; HIRATA, 1988).

O método GOD (FOSTER; HIRATA, 1988) corresponde a uma das técnicas de determinação de vulnerabilidade mais utilizadas devido a sua simplicidade de conceitos e implementação, uma vez que utiliza dados básicos de estudos hidrogeológicos, como o grau de inacessibilidade hidráulica da zona saturada e a capacidade de atenuação da zona não saturada.

Os valores dos índices calculados foram espacializados utilizando o software SURFER $^{\circledR}$ versão 7.0 (1999), gerando o mapa de vulnerabilidade GOD, apresentado na Figura 21.

Finalizando a pesquisa, os mapas de distribuição dos valores dos parâmetros físicoquímicos foram comparados com o mapa do grau de vulnerabilidade dos aquíferos locais, identificando as áreas que apresentaram comprometimento da qualidade das águas e que estão em áreas de risco quanto à vulnerabilidade natural dos aquíferos.

\section{RESULTADOS E DISCUSSÃO}

A análise da qualidade da água correspondeu à determinação das principais estatísticas dos valores dos parâmetros físicos e químicos constantes dos relatórios da CASAL relativos às águas brutas coletadas em 27 poços para o ano de 2008 e 19 poços para o ano de 2018 na área de estudo.

Considerando que essas águas são usadas prioritariamente para consumo humano, os resultados foram interpretados com base na Portaria n ${ }^{\circ}$ 2914/2011 do Ministério da Saúde, na Resolução CONAMA n ${ }^{\circ}$ 335/2003 e suas alterações, a partir dos parâmetros estatísticos calculados e dos gráficos que ilustram os resultados do monitoramento.

Os parâmetros físicos que apresentaram comprometimento da qualidade das águas foram cor e turbidez, enquanto os parâmetros químicos com valores fora dos padrões de qualidade da água foram $\mathrm{pH}$, acidez, cloretos, amônia e nitrato, todos disponíveis nos relatórios das análises da CASAL. Os resultados constam da tabela 1 e são apresentados a seguir. 
Revista de Geografia (Recife) V. 37, No. 3, 2020

Tabela 1. Análise estatística dos parâmetros físico-químicos

\begin{tabular}{|c|c|c|c|c|c|c|c|c|c|c|c|c|c|c|c|c|}
\hline \multirow{2}{*}{ PARÂMETRO } & \multicolumn{2}{|c|}{ MÍNIMO } & \multicolumn{2}{|c|}{ MÁXIMO } & \multicolumn{2}{|c|}{ MÉDIA } & \multicolumn{2}{|c|}{ MEDIANA } & \multicolumn{2}{|c|}{ VARIÂNCIA } & \multicolumn{2}{|c|}{$\begin{array}{l}\text { DESVIO- } \\
\text { PADRÃO }\end{array}$} & \multicolumn{2}{|c|}{ ASSIMETRIA } & \multicolumn{2}{|c|}{ CURTOSE } \\
\hline & 2008 & 2018 & 2008 & 2018 & 2008 & 2018 & 2008 & 2018 & 2008 & 2018 & 2008 & 2018 & 2008 & 2018 & 2008 & 2018 \\
\hline $\mathrm{pH}$ & 4,17 & 3,81 & 5,86 & 6,69 & 4,70 & 4,47 & 4,62 & 4,30 & 0,17 & 0,39 & 0,412 & 0,62 & 1,28 & 2,80 & 1,21 & 9,55 \\
\hline Cor & 0,00 & 2,00 & 175,00 & 11,00 & 6,48 & 6,16 & 0,00 & 6,00 & 1134,26 & 8,92 & 33,679 & 2,99 & 5,20 & 0,14 & 27,00 & $-1,25$ \\
\hline Turbidez & 0,22 & 0,59 & 32,50 & 4,12 & 3,61 & 1,79 & 1,06 & 1,22 & 69,27 & 1,49 & 8,323 & 1,22 & 3,36 & 1,13 & 10,26 & $-0,39$ \\
\hline $\begin{array}{l}\text { Condutância } \\
\text { Especifica }\end{array}$ & 28,10 & 27,50 & 364,00 & 140,30 & 101,49 & 73,20 & 80,70 & 62,70 & 4828.53 & 904,19 & 69,488 & 30,07 & 2,30 & 1.18 & 7,06 & 1,15 \\
\hline Acidez & 8,00 & 12,00 & 44,00 & 78,00 & 21,26 & 31,05 & 22,00 & 28,00 & 80,05 & 222,83 & 8,947 & 14,93 & 0,76 & 1,82 & 0,38 & 4,63 \\
\hline Alcalinidade $\mathrm{HCO}_{3}$ & 2,00 & 2,00 & 28,00 & 120,00 & 7,85 & 11,89 & 8,00 & 6,00 & 27,98 & 688,21 & 5,289 & 26,23 & 2,63 & 4,33 & 8,40 & 18,81 \\
\hline Dureza Total & 4,00 & 6,00 & 50,00 & 132,00 & 16,67 & 19,56 & 12,00 & 14,00 & 152,31 & 777,54 & 12,341 & 27,88 & 1,47 & 4,03 & 1,52 & 16,97 \\
\hline Cálcio & 2,00 & 0,00 & 20,00 & 56,00 & 5,93 & 6,21 & 6,00 & 4,00 & 19,23 & 148,84 & 4,385 & 12,20 & 1,78 & 4,19 & 3,59 & 17,97 \\
\hline Magnésio & 0,00 & 2,00 & 48,00 & 76,00 & 10,74 & 13,36 & 8,00 & 8,00 & 107,74 & 256,63 & 10,380 & 16,02 & 2,15 & 3,65 & 5,81 & 14,63 \\
\hline Cloretos & 9,00 & 8,30 & 120,00 & 119,10 & 22,63 & 32,09 & 18,00 & 25,00 & 447,17 & 663,24 & 21,146 & 25,75 & 4,04 & 2,47 & 18,49 & 7,08 \\
\hline Silica & 0,82 & 3,40 & 3,97 & 11,80 & 3,17 & 8,46 & 3,25 & 8,50 & 0,31 & 3,35 & 0,557 & 1,83 & $-2,95$ & $-0,78$ & 12,39 & 2,66 \\
\hline Sulfatos & 0,00 & 0,20 & 4,65 & 8,30 & 0,76 & 2,21 & 0,51 & 1,80 & 1,06 & 5,03 & 1,028 & 2,24 & 2,51 & 1,79 & 7,48 & 2,96 \\
\hline Amônia & 0,00 & 0,00 & 1,92 & 0,80 & 0,22 & 0,17 & 0,01 & 0,10 & 0,20 & 0,04 & 0,449 & 0,20 & 2,68 & 2,53 & 7,62 & 6,04 \\
\hline Nitrato & 0,00 & 1,69 & 0,00 & 9,08 & 0,00 & 5,06 & 0,00 & 5,98 & 0,00 & 6,82 & 0,000 & 2,61 & 0,00 & 0,00 & 0,00 & $-1,64$ \\
\hline Nitrito & 0,00 & 0,00 & 0,02 & 0,02 & 0,00 & 0,00 & 0,00 & 0,00 & 0,00 & 0,00 & 0,004 & 0,00 & 4,05 & 4,36 & 16,71 & 19,00 \\
\hline Ferro Total & 0,06 & 0,00 & 3,44 & 0,26 & 0,31 & 0,11 & 0,18 & 0,08 & 0,40 & 0,01 & 0,631 & 0,08 & 5,06 & 0,40 & 26,01 & $-0,99$ \\
\hline Sódio & 6,00 & 6,00 & 65,20 & 23,00 & 22,08 & 14,83 & 21,00 & 16,00 & 150,00 & 24,69 & 12,247 & 4,97 & 1,70 & $-0,28$ & 4,83 & $-0,81$ \\
\hline Potássio & 0,20 & 0,00 & 2,40 & 2,00 & 0,93 & 0,75 & 0,70 & 1,00 & 0,40 & 0,30 & 0,633 & 0,54 & 1,10 & $-0,04$ & 0,33 & 0,07 \\
\hline $\mathrm{CO} 2$ & 31,59 & 49,70 & 1097,90 & 1886,50 & 375,20 & 637,75 & 292,18 & 610,40 & 74202,22 & 233572,21 & 272,401 & 483,29 & 0,82 & 1,36 & 0,27 & 2,09 \\
\hline Sólidos Totais & 22,00 & 28,00 & 278,00 & 198,00 & 88,15 & 90,63 & 70,00 & 92,00 & 3811,05 & 1949,80 & 61,734 & 44,16 & 1,59 & 0,57 & 2,75 & 0,56 \\
\hline
\end{tabular}

Fonte: Elaborado pelo autor (2019)

A distribuição espacial se constituiu basicamente da análise dos mapas de contornos, relativos às águas coletadas nos poços (Figuras 2 e 3 ) de propriedade da CASAL, existentes na bacia endorreica do Tabuleiro do Martins, Maceió-AL, período 2008 e 2018.

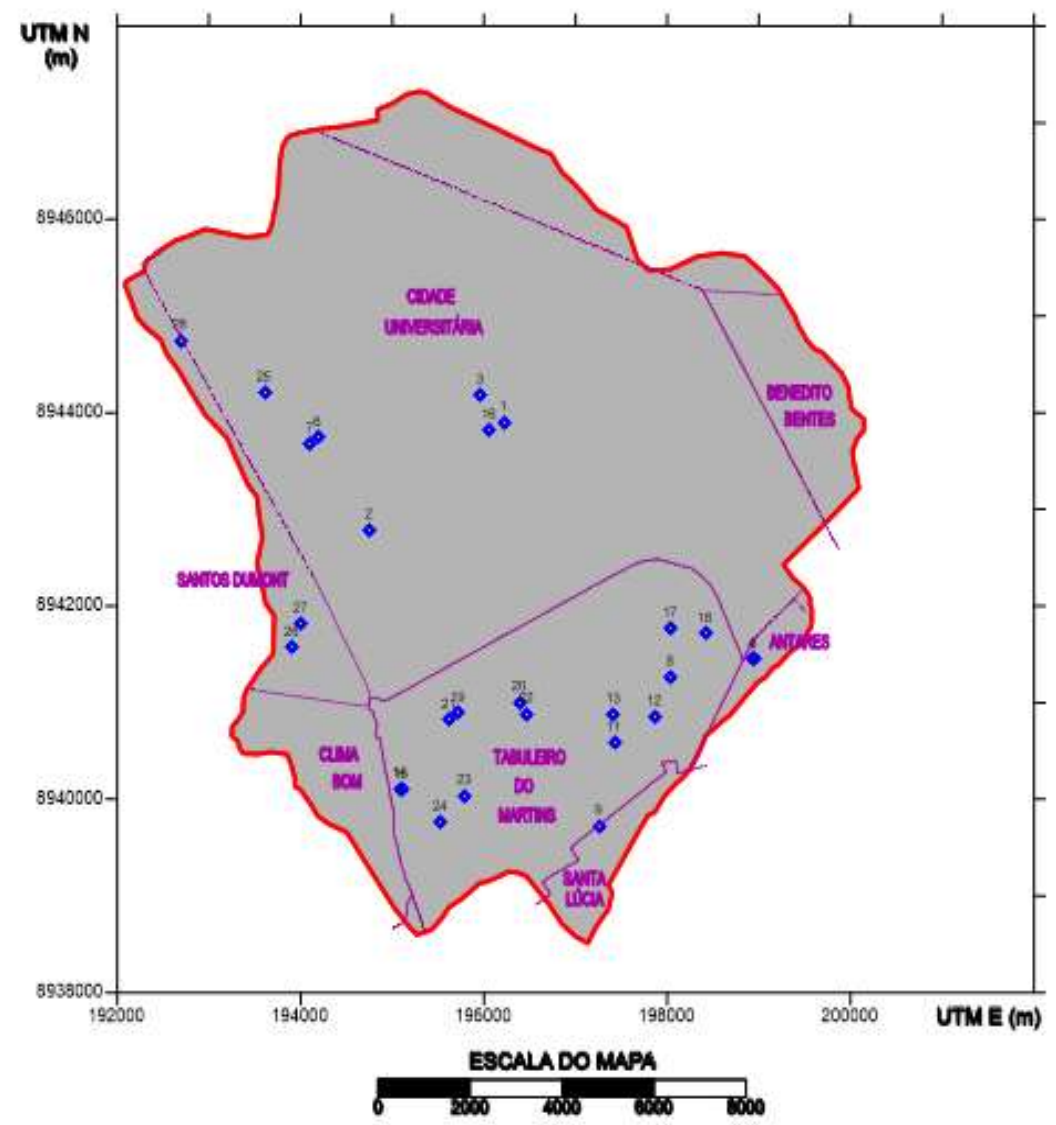

Figura 2. Distribuição dos poços da bacia endorreica do Tabuleiro do Martins de 2008

Fonte: Elaborado pelo autor (2019) 
Revista de Geografia (Recife) V. 37, N. 3, 2020

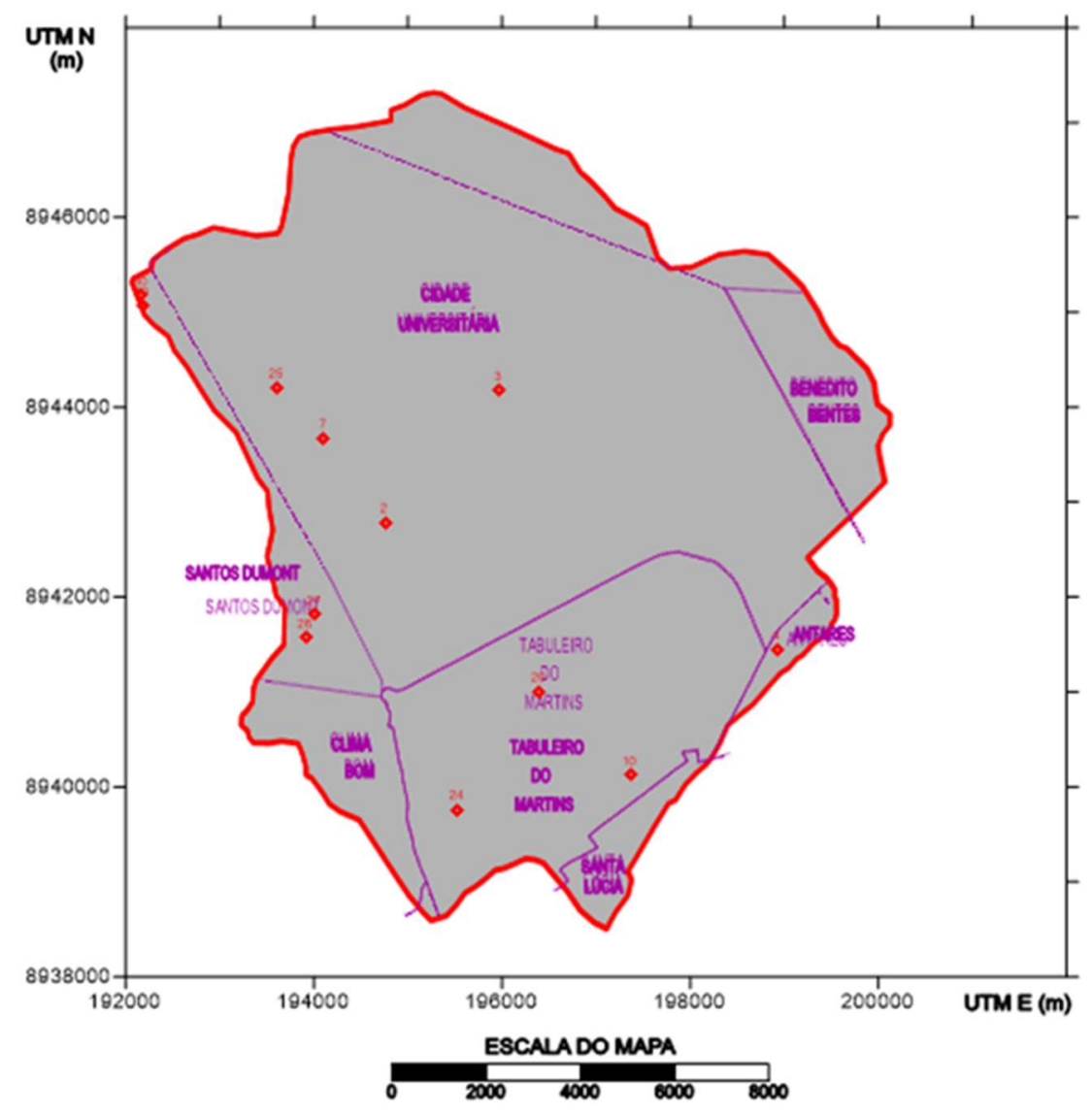

Figura 3. Distribuição dos poços da bacia endorreica do Tabuleiro do Martins de 2018

Fonte: Elaborado pelo autor (2019)

$p H$

As águas subterrâneas locais variaram de ácidas a neutras. Segundo a portaria $n^{\circ}$ 2914/2011 do Ministério da Saúde que estabelece os limites de 6,0 a 9,5 para o pH, em todos os poços estudados no ano de 2008 as águas não são adequadas para o consumo humano (Figura 4). 


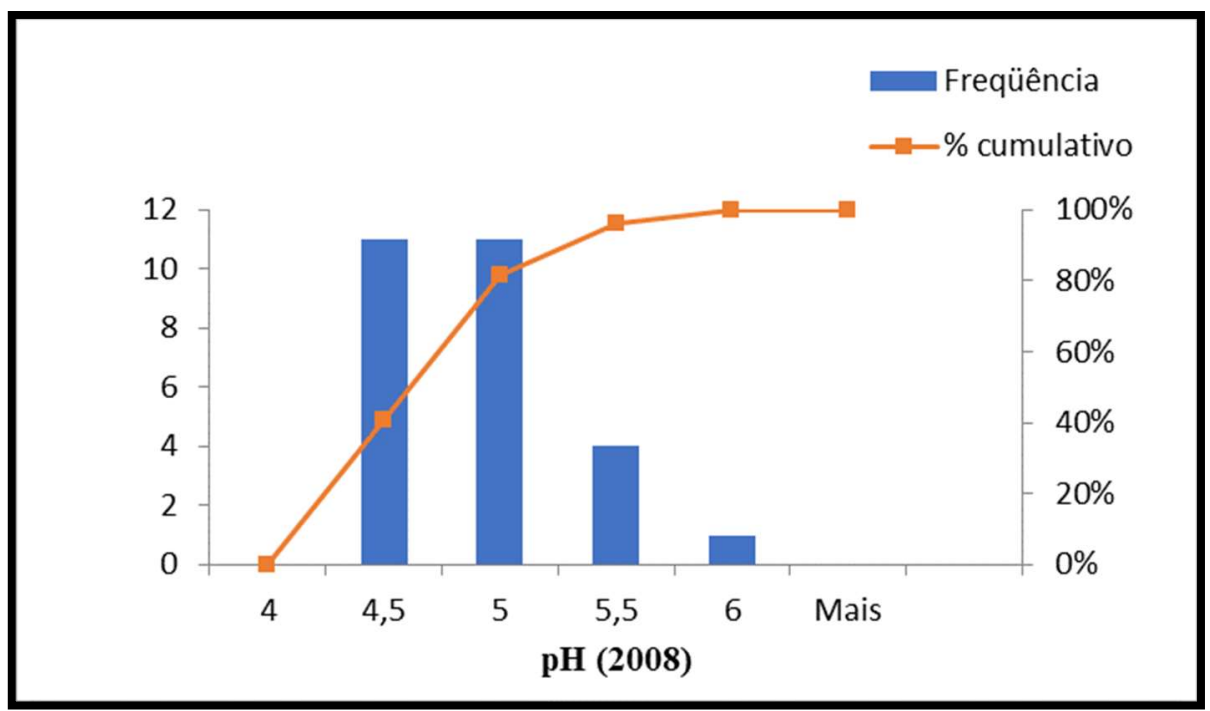

Figura 4. Histograma do $\mathrm{pH}$ da água nos poços do Tabuleiro do Martins em 2008

Fonte: Elaborado pelo autor (2019)

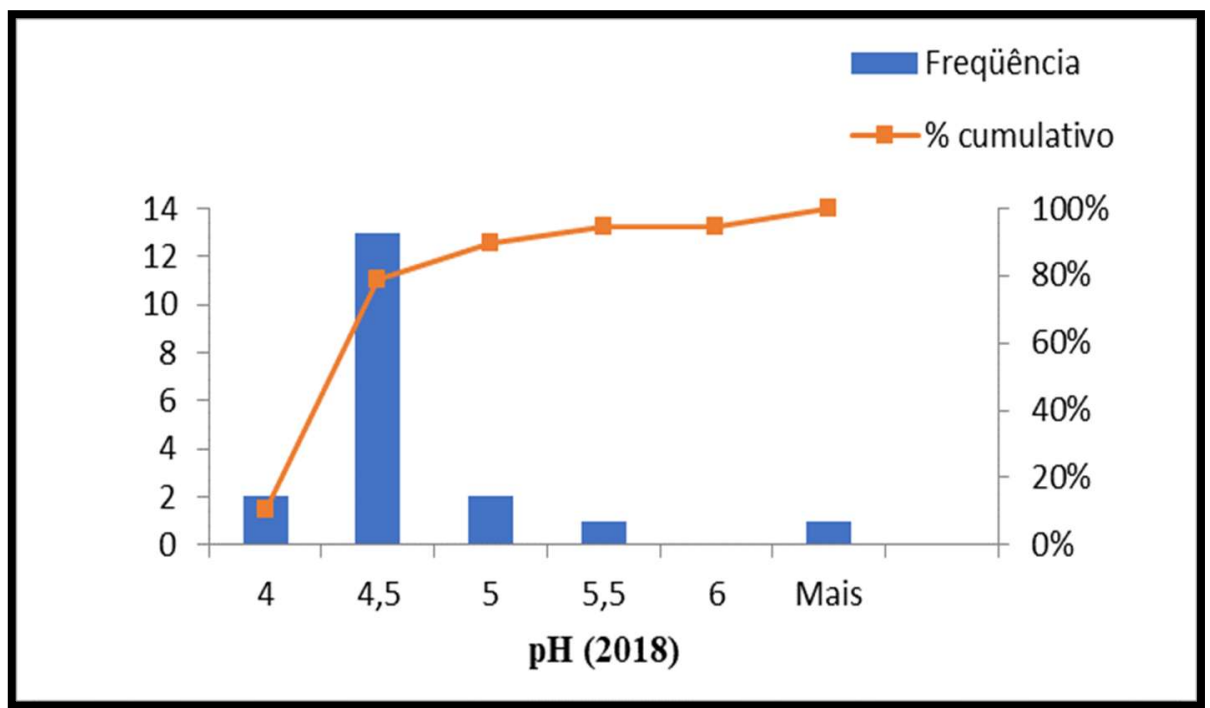

Figura 5. Histograma do $\mathrm{pH}$ da água nos poços do Tabuleiro do Martins em 2018

Fonte: Elaborado pelo autor (2019)

No ano de 2018 (Figura 5) o poço PLSL-02 situado no conjunto Salvador Lyra apresentou $\mathrm{pH}$ de 6,69 , único no referido ano com $\mathrm{pH}$ dentro dos padrões adequados para consumo humano.

No caso da bacia endorreica do Tabuleiro do Martins observa-se uma acidificação da água no período estudado, de 2008 a 2018, conforme mostrada na figura 6, corroborando com uma possível contaminação por esgoto. 


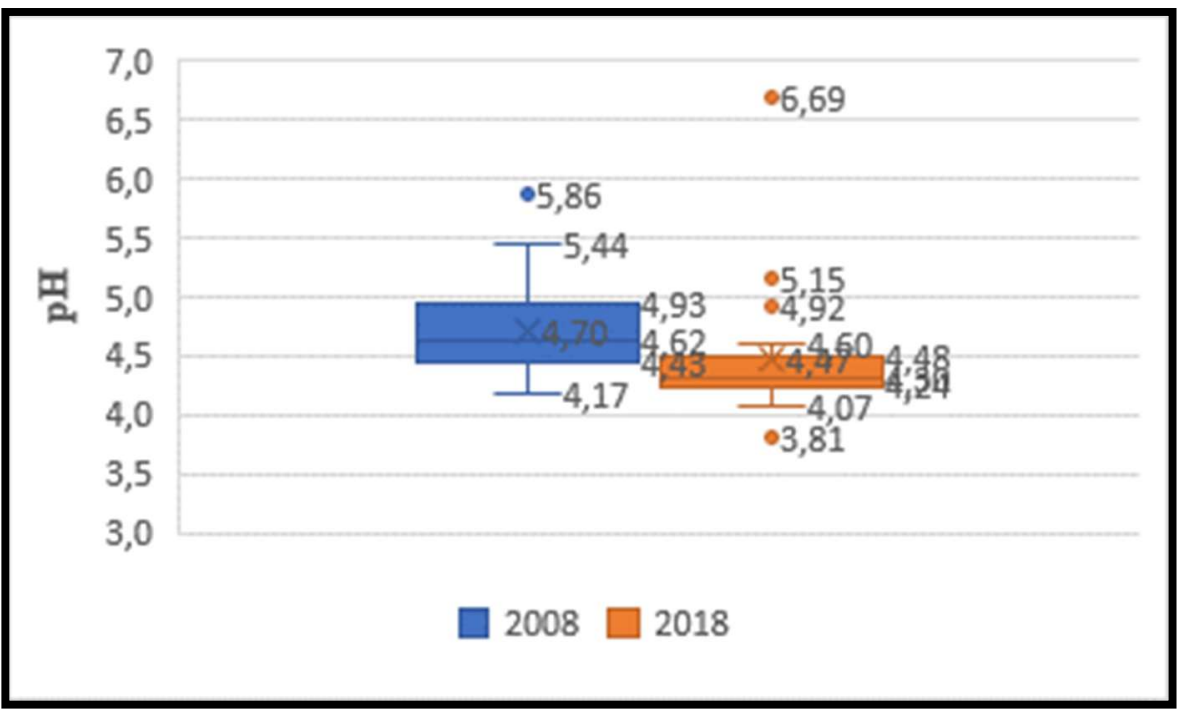

Figura 6. Bloxpot do pH da água nos poços do Tabuleiro do Martins de 2008 e 2018

Fonte: Elaborado pelo autor (2019)

\section{Cor aparente}

No período de 2018 (Figura 7), verifica-se uma mudança drástica ao comparar com os dados do ano de 2008, onde a cor aparente foi igual a $0 \mathrm{uH}$.

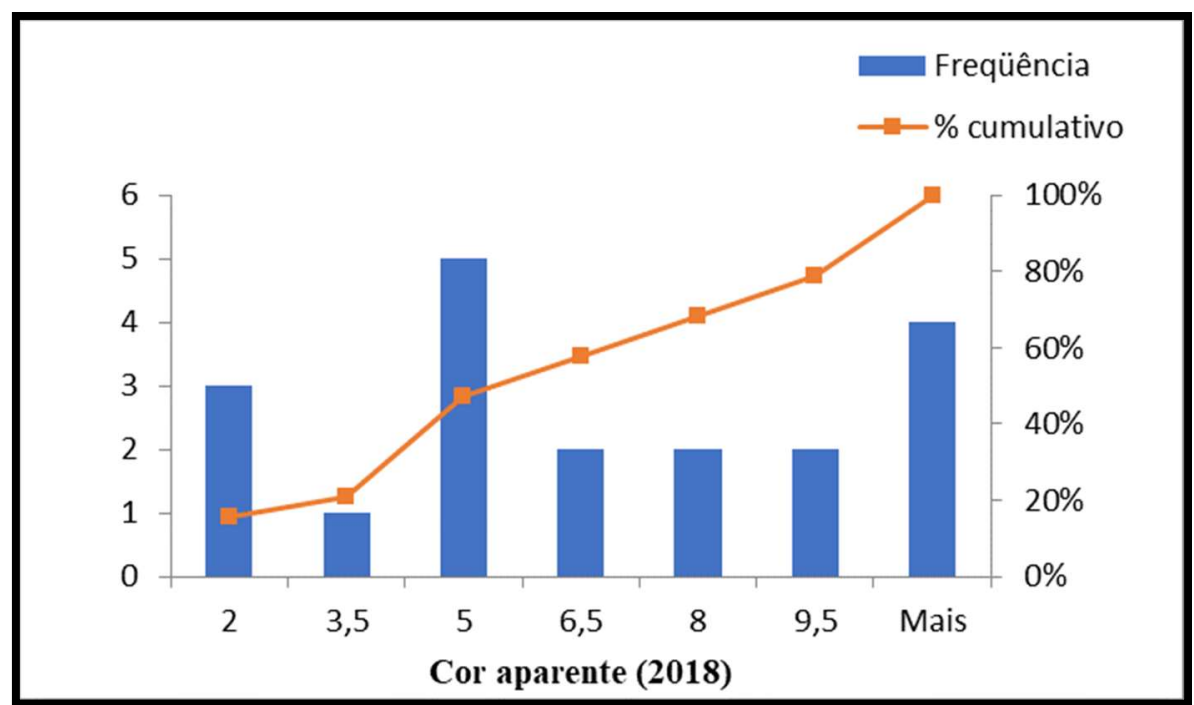

Figura 7. Histograma da cor aparente da água nos poços do Tabuleiro do Martins em 2018 Fonte: Elaborado pelo autor (2019)

Para atender o padrão de potabilidade, a água deve apresentar intensidade de cor aparente inferior a 5,0 uH. Dados colhidos em 2018 mostraram que mais da metade dos poços analisados apresentaram cor acima de 5,0 uH, destacando-se o poço PCB-06 (poço Clima Bom) cuja cor aparente apresentou 11,0 uH (Figura 8). 
Valores elevados de cor aparente são característicos de águas com presença considerável de partículas em suspensão.

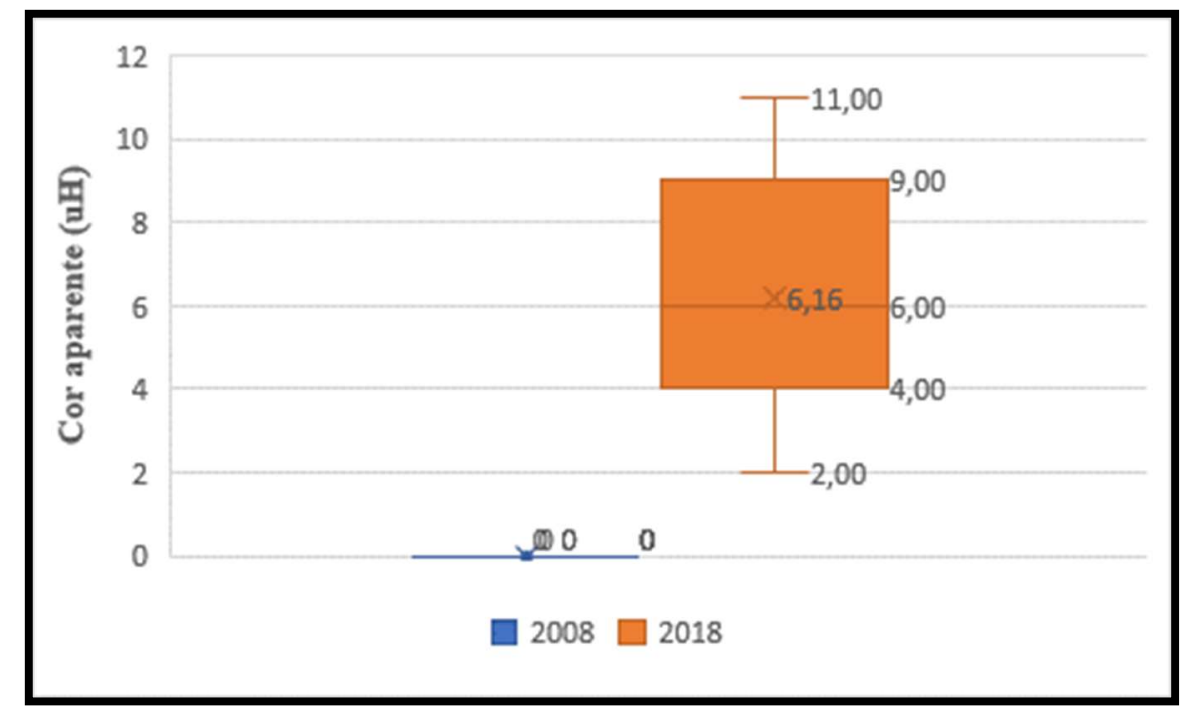

Figura 8. Bloxpot da cor aparente da água nos poços do Tabuleiro do Martins de 2008 e 2018 Fonte: Elaborado pelo autor (2019)

\section{Turbidez}

Os dados de 2008 (Figura 9) apresentam relevância ao analisarmos os poços PCB-06 (poço Clima Bom) e PHV-03 (poço Hélio Vasconcelos), com turbidez 32,02 uT e 32,05 uT, respectivamente.

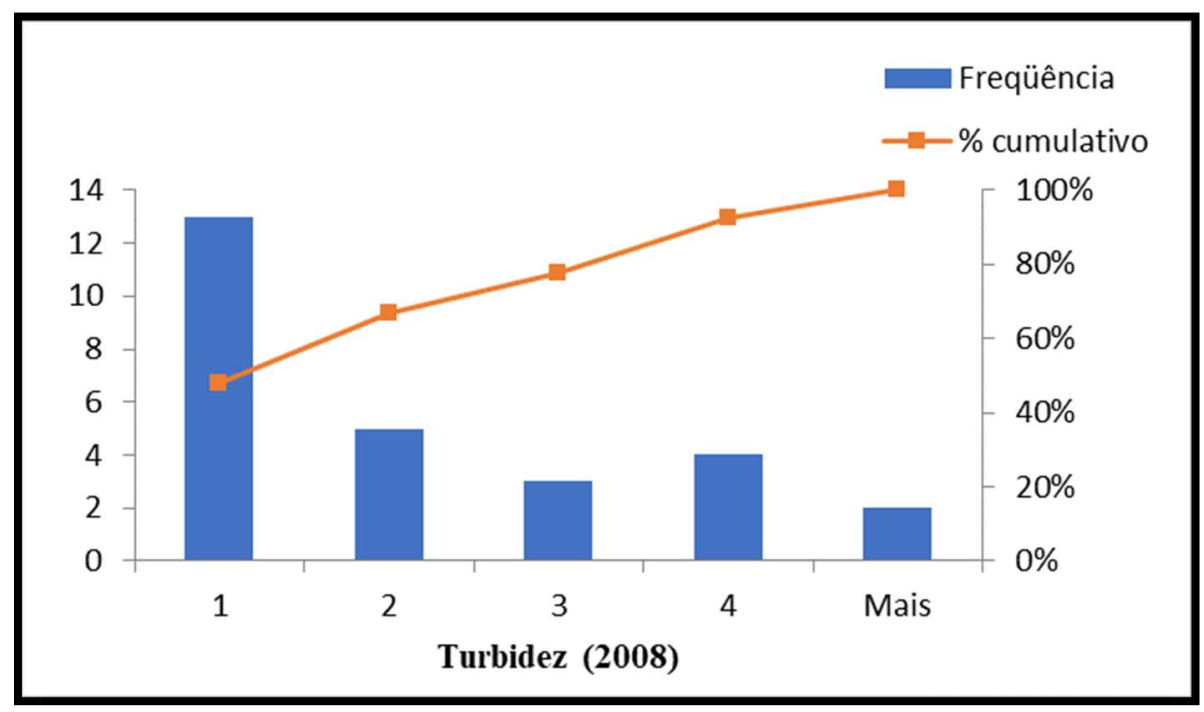

Figura 9. Histograma da turbidez da água nos poços do Tabuleiro do Martins em 2008 Fonte: Elaborado pelo autor (2019)

No ano de 2018 (Figura 10), maior parte dos dados está fora do padão estabelecido. No Brasil, o padrão de potabilidade para turbidez definido pela Portaria $n^{\circ} 36 / 1990$ do Ministério da Saúde é de 1,0 uT. 


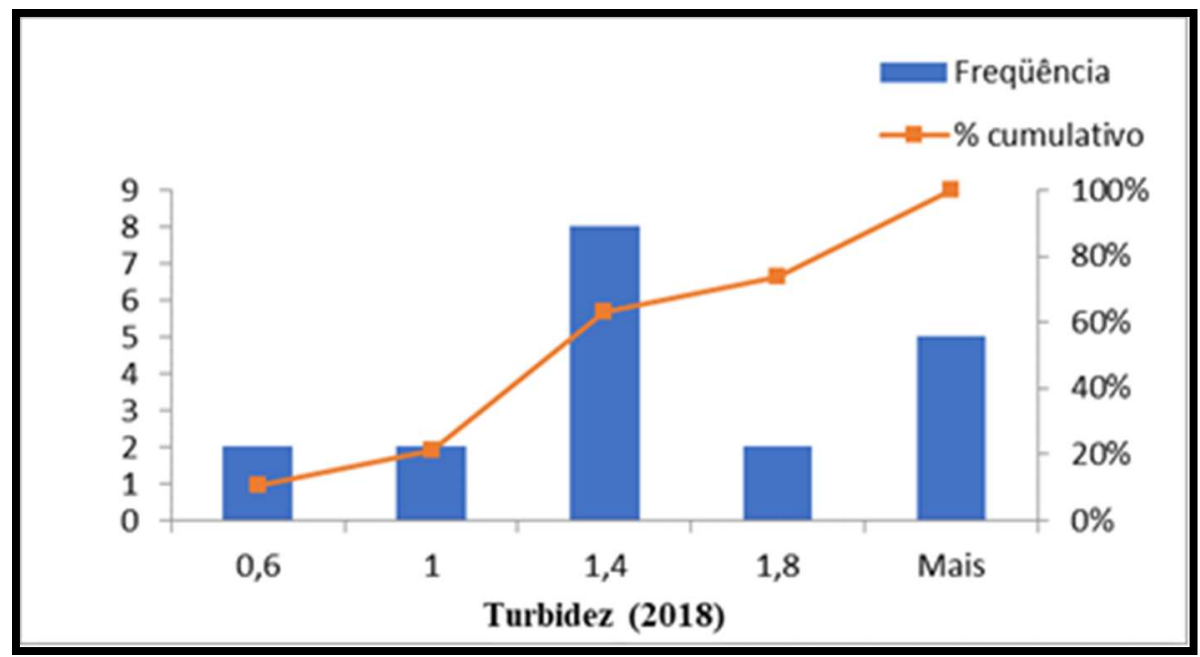

Figura 10. Histograma da turbidez da água nos poços do Tabuleiro do Martins em 2018

Fonte: Elaborado pelo autor (2019)

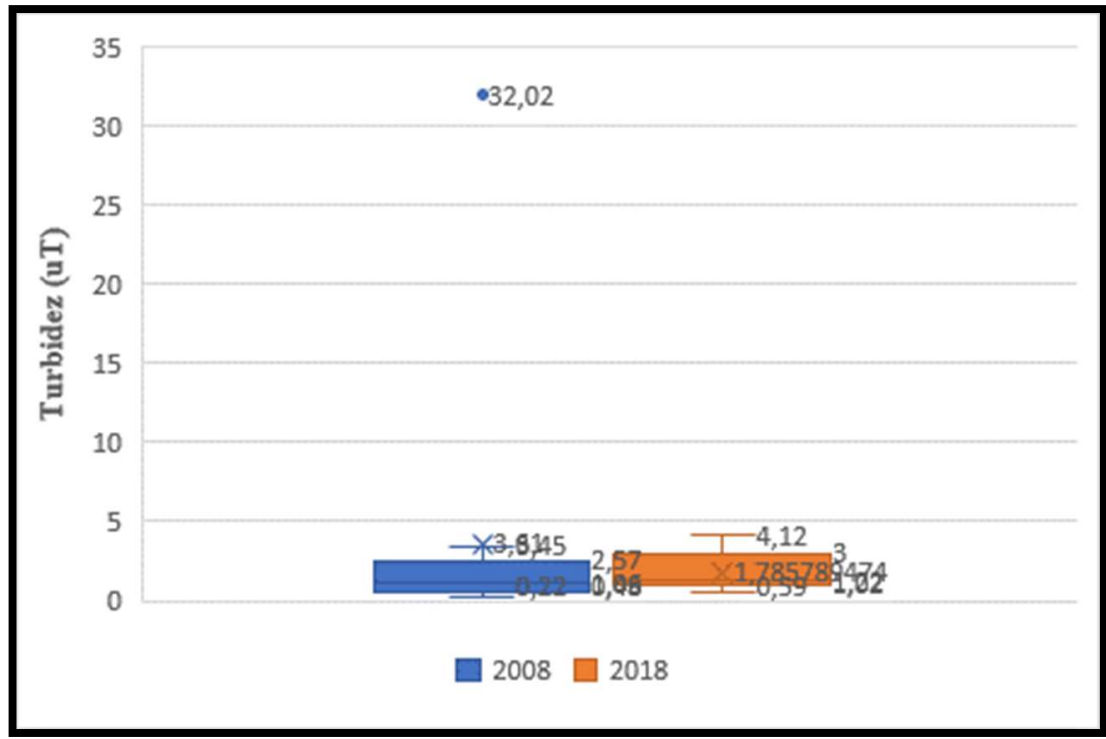

Figura 11. Bloxpot da turbidez da água nos poços do Tabuleiro do Martins de 2008 e 2018

Fonte: Elaborado pelo autor (2019)

Por apresentar um provável erro grosseiro (podendo ter ocorrido por uma leitura errônea, operação indevida ou falha no sistema de medição) de 32,02 uT (poço PCB 06-Clima Bom) para o ano de 2008, o bloxpot de turbidez foi refeito, expurgando o valor referido (Figura $11)$.

Acidez

No período de 2008 (Figura 12), caracteriza-se por uma concentração significativa de ácidos, denominando assim como uma acidez carbônica. 


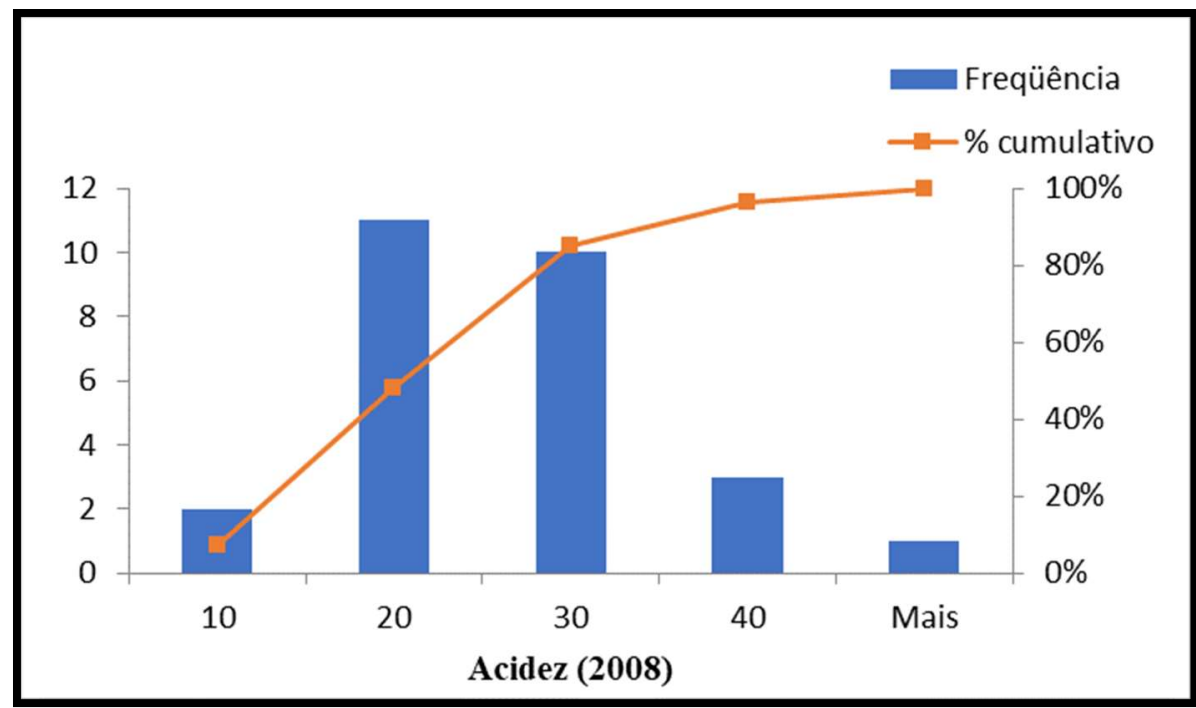

Figura 12. Histograma da acidez da água nos poços do Tabuleiro do Martins em 2008

Fonte: Elaborado pelo autor (2019)

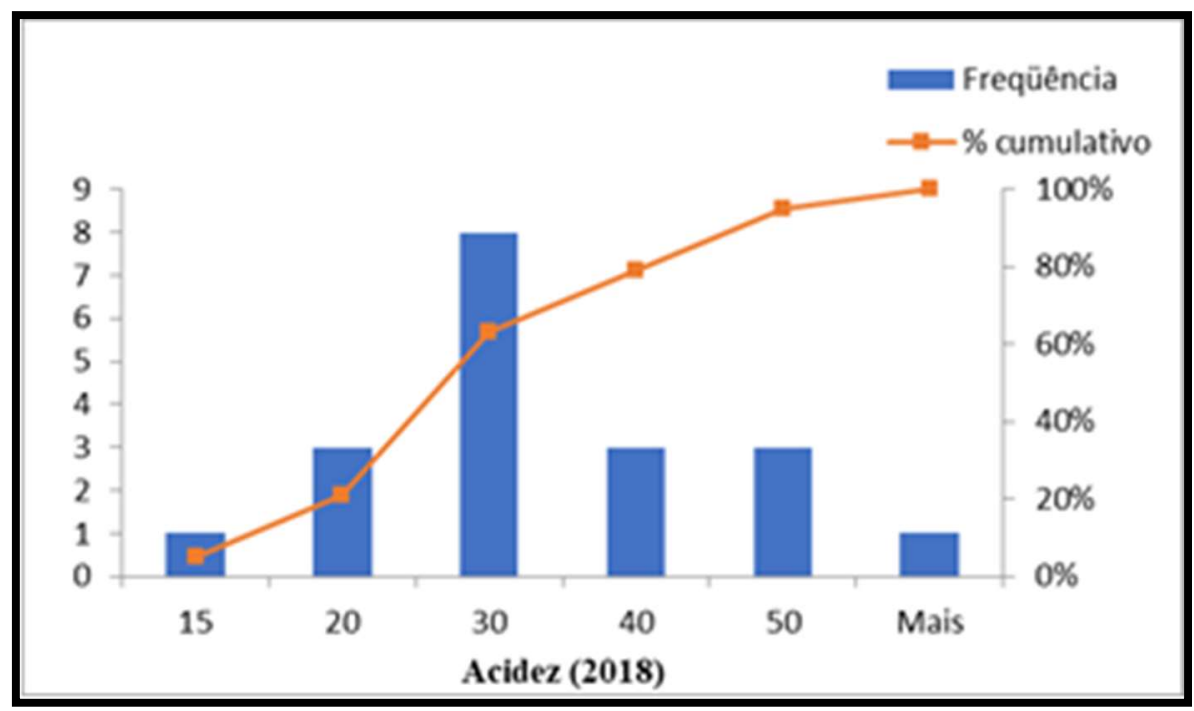

Figura 13. Histograma da acidez da água nos poços do Tabuleiro do Martins em 2018

Fonte: Elaborado pelo autor (2019)

No período de 2018 (Figura 13), os dados mediante acidez continuam altos, permanecendo na classificação denominada como acidez carbônica.

Os dados de 2008 e 2018 (Figura 14), corroboram para um possível processo de acidificação das águas da bacia endorreica do Tabuleiro do Martins. 
Revista de Geografia (Recife) V. 37, N. 3, 2020

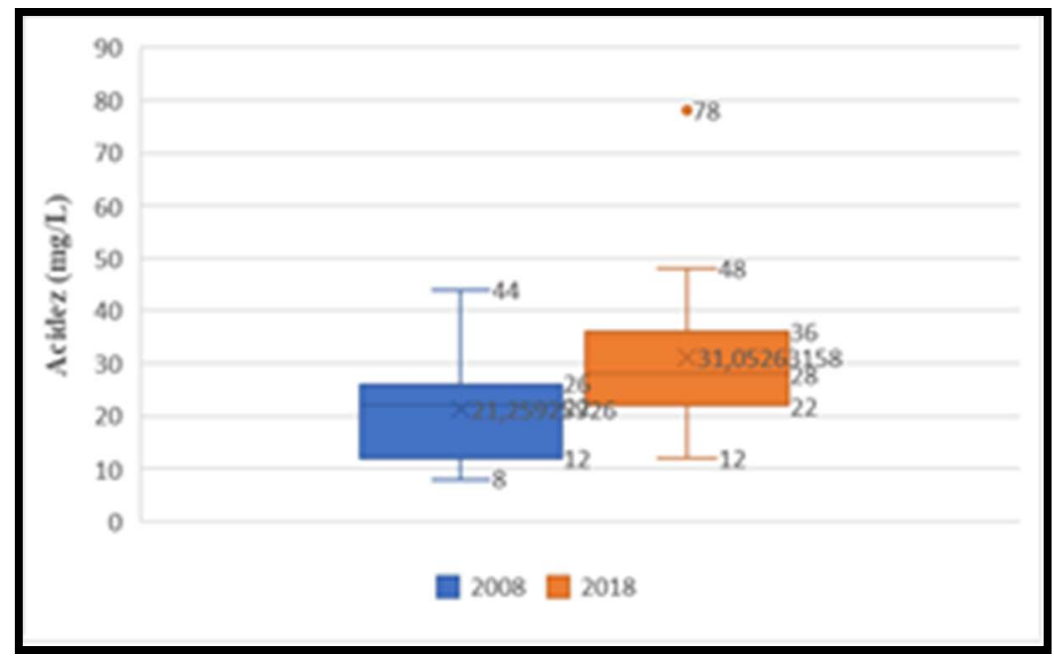

Figura 14. Bloxpot da acidez da água nos poços do Tabuleiro do Martins de 2008 e 2018

Fonte: Elaborado pelo autor (2019)

\section{Cloretos}

No ano de 2008 (Figura 15) o poço PJDL-01A situado no conjunto José Dubeaux Leão apresentou cloreto de $120 \mathrm{~m} / \mathrm{L}$, único no referido ano apresentando cloretos fora do padrão adequado para consumo.

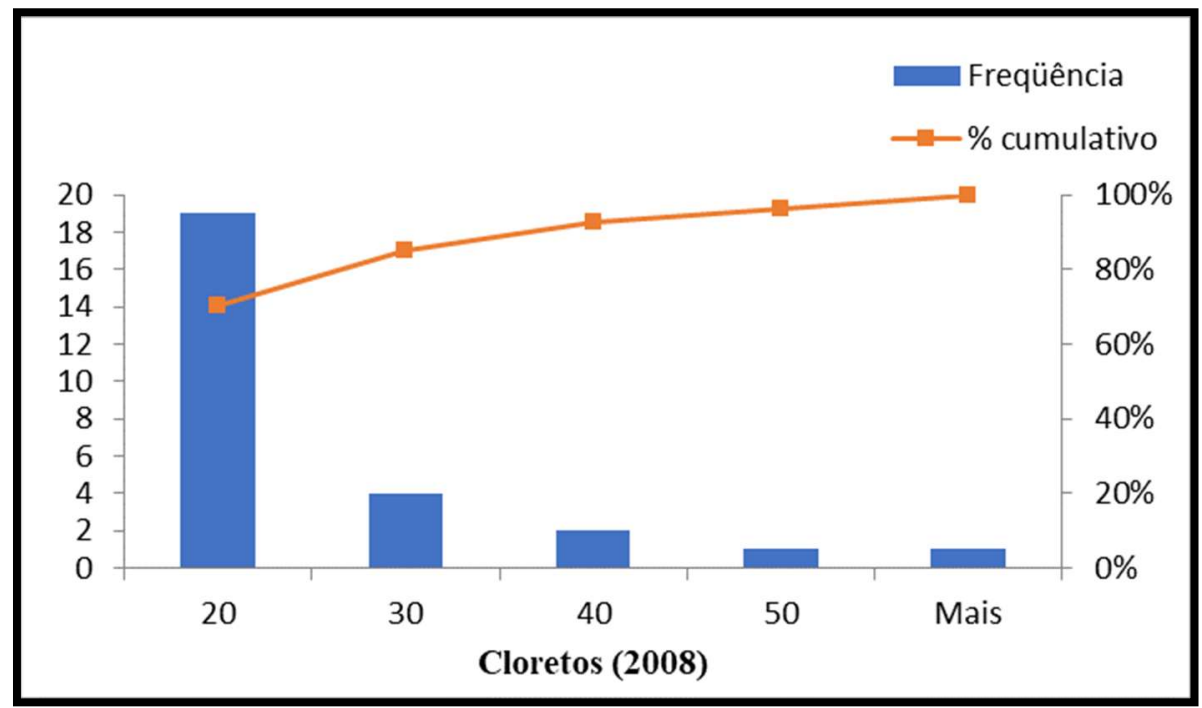

Figura 15. Histograma de cloretos da água nos poços do Tabuleiro do Martins em 2008

Fonte: Elaborado pelo autor (2019) 


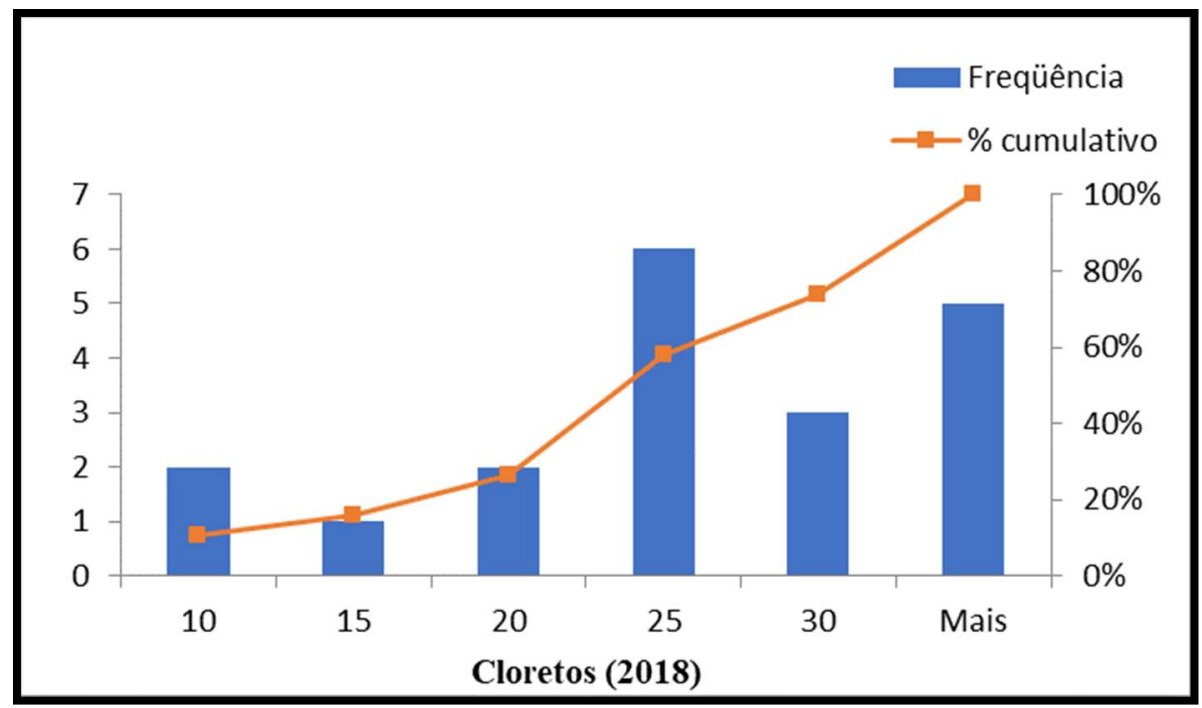

Figura 16. Histograma de cloretos da água nos poços do Tabuleiro do Martins em 2018

Fonte: Elaborado pelo autor (2019)

No ano de 2018 (Figura 16) o poço PCU-01 situado no conjunto Cidade Universitária, apresentou cloreto de $119,1 \mathrm{~m} / \mathrm{L}$, único no referido ano apresentando cloreto fora do padrão adequado para consumo.

Observamos aumento dos cloretos ao compararmos os dados de 2008 e 2018 (Figura 17), constatando eventual acréscimo no parâmetro analisado.

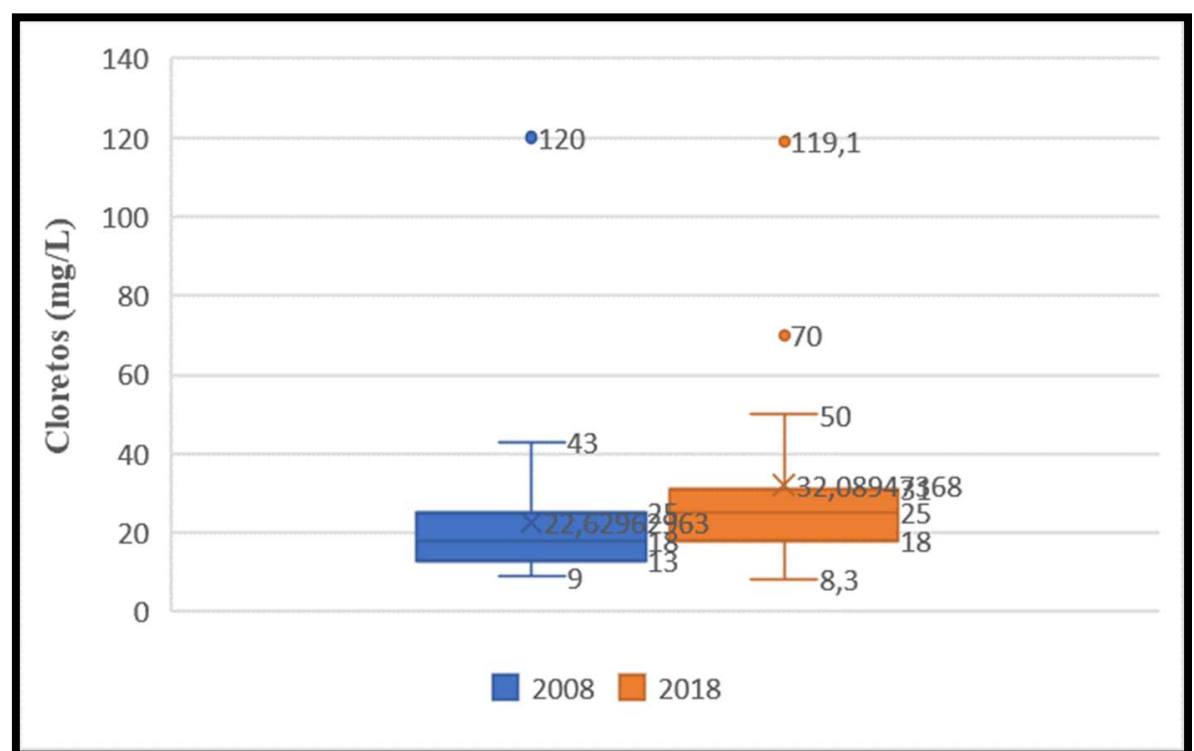

Figura 17. Bloxpot de cloretos da água nos poços do Tabuleiro do Martins de 2008 e 2018

Fonte: Elaborado pelo autor (2019)

\section{Amônia}

Amônia pode estar presente naturalmente em águas superficiais ou subterrâneas, sendo que usualmente sua concentração é bastante baixa devido à sua fácil adsorção por partículas do 
solo ou à oxidação a nitrito e nitrato. Entretanto, a ocorrência de concentrações elevadas pode ser resultante de fontes de poluição próximas como fossas sépticas individuais ou condominiais, bem como da redução de nitrato por bactérias ou por íons ferrosos presentes no solo (ALABURDA; NISHIHARA, 1998).

No ano de 2008 (Figura 18) o poço PT-01 situado no bairro Tabuleiro do Martins, apresentou amônia de 1,92mg/L, podendo caracterizar contaminação.

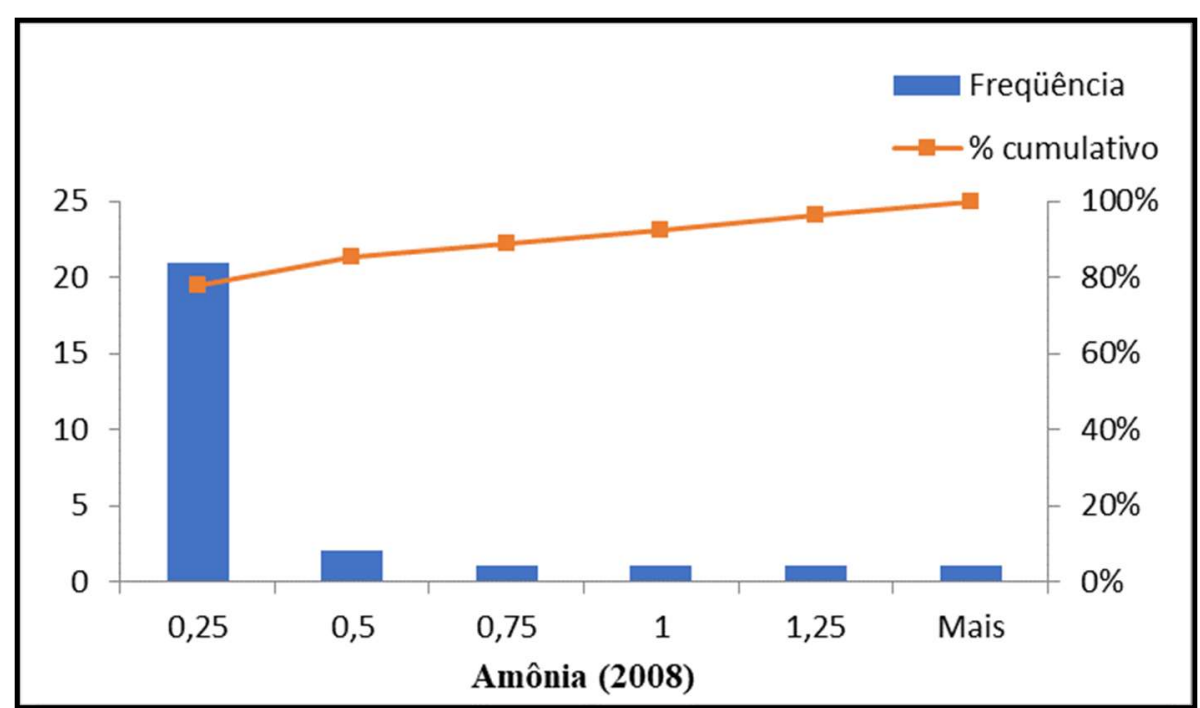

Figura 18. Histograma de amônia da água nos poços do Tabuleiro do Martins em 2008

Fonte: Elaborado pelo autor (2019)

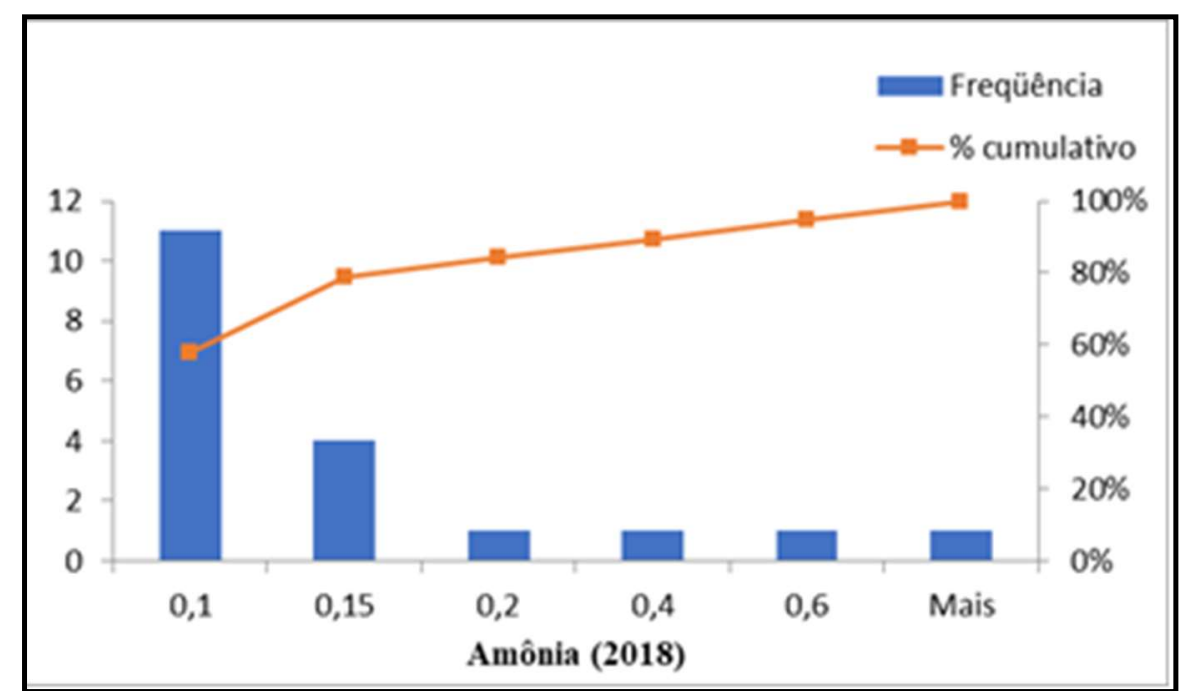

Figura 19. Histograma de amônia da água nos poços do Tabuleiro do Martins em 2018 Fonte: Elaborado pelo autor (2019)

No ano de 2018 (Figura 19) todos os poços apresentaram teores dentro do padrão. $\mathrm{Na}$ figura 20, detecta-se uma relativa melhora nos dados de 2008 para 2018. 


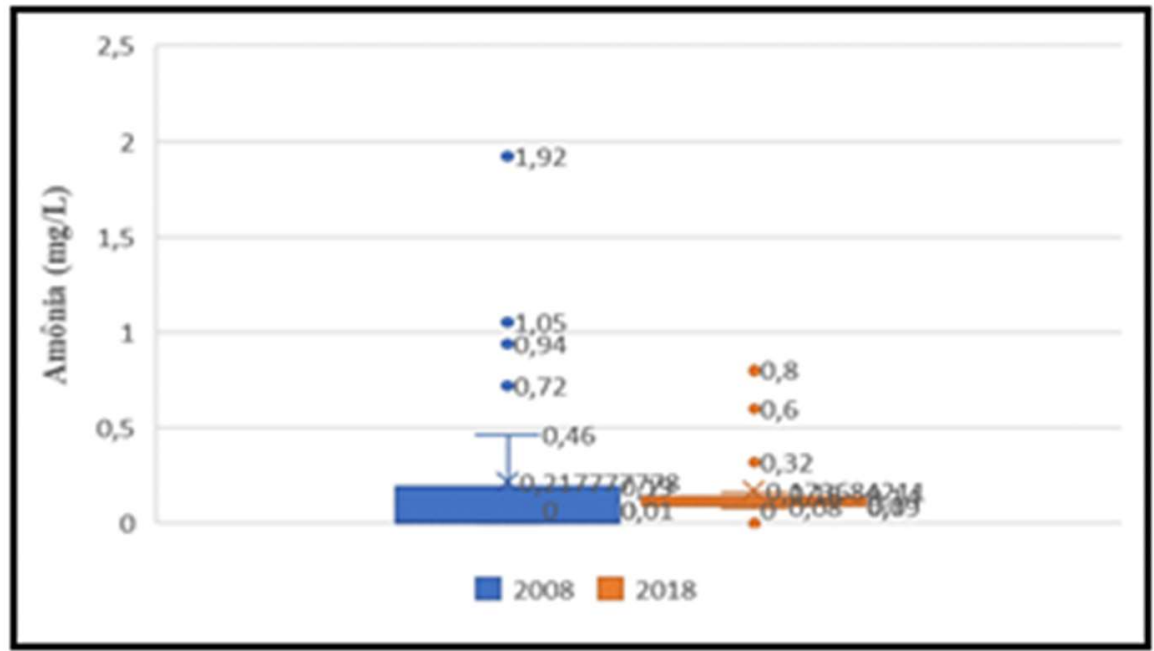

Figura 20. Bloxpot de amônia da água nos poços do Tabuleiro do Martins de 2008 e 2018

Fonte: Elaborado pelo autor (2019)

Nitrato

Os dados analisados do nitrato no ano de 2018 (Figura 21) são preocupantes por apresentarem nove poços (PHE-01, PIN-02, PLSL-02, PCB-05, PCB-06, PMAL-01, PMAL02, PCJ-03 e PCJS-02) ultrapassando teores acima de 5mg/L.

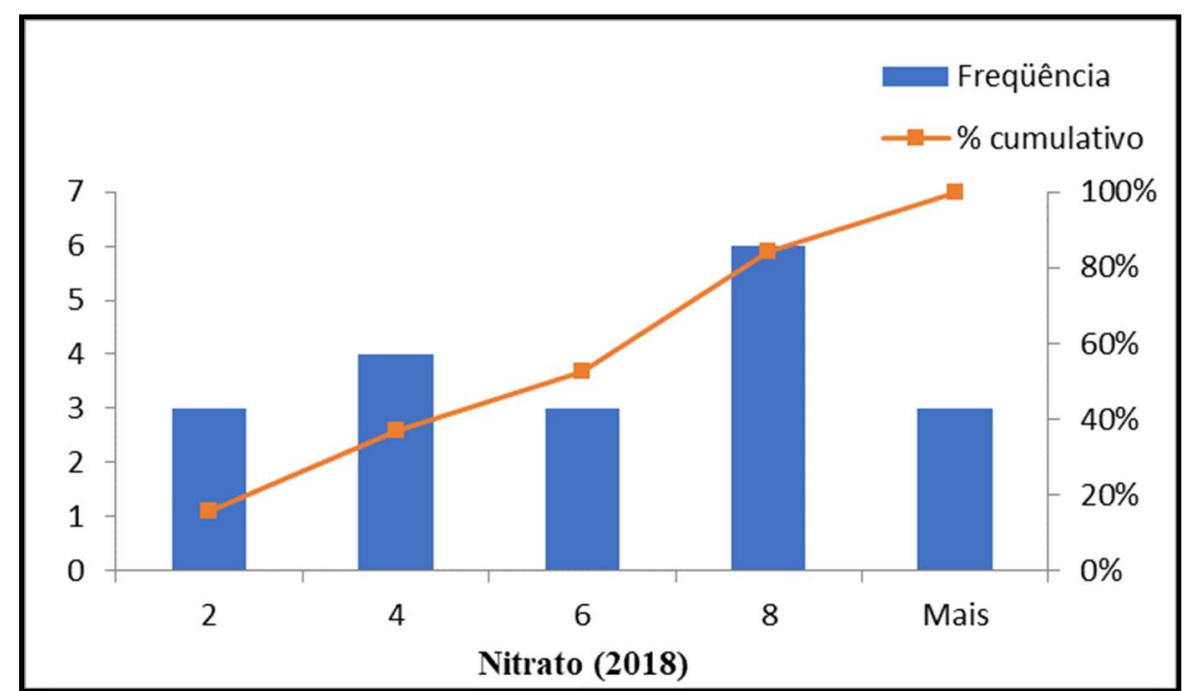

Figura 21. Histograma de nitrato da água nos poços do Tabuleiro do Martins em 2018

Fonte: Elaborado pelo autor (2019)

Observando a figura 22 do nitrato, há grande possibilidade de contaminação por dejetos pela total inexistência do mesmo no ano de 2008. 


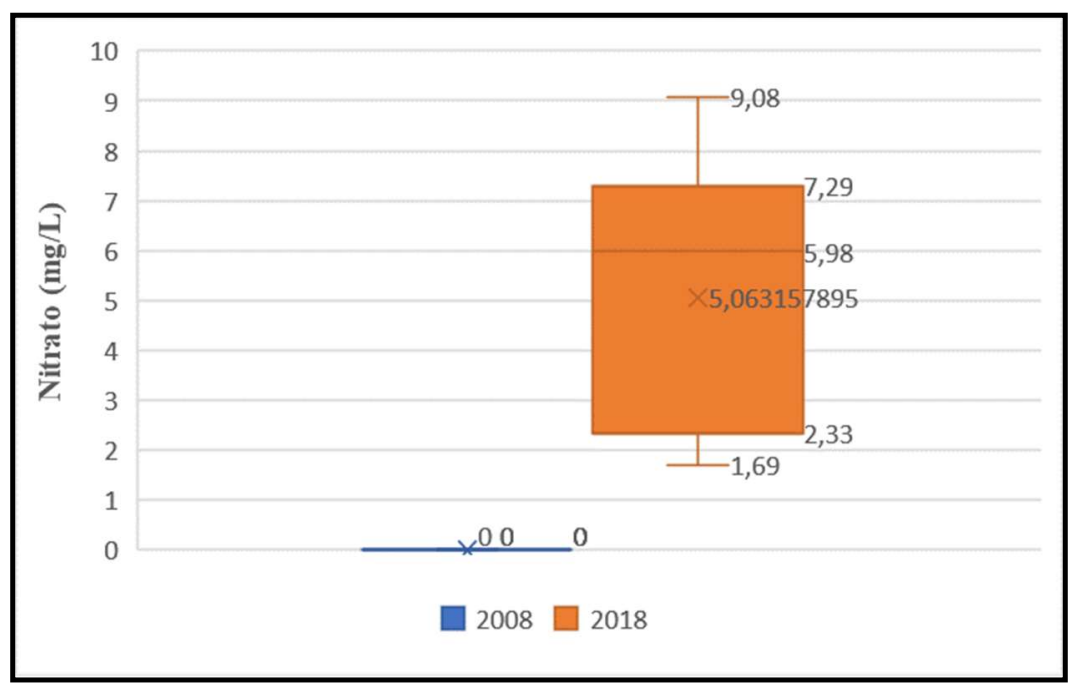

Figura 22. Bloxpot de nitrato da água nos poços do Tabuleiro do Martins de 2008 e 2018

Fonte: Elaborado pelo autor (2019)

\section{Vulnerabilidade da bacia endorreica do Tabuleiro do Martins}

A vulnerabilidade natural da bacia endorreica do Tabuleiro do Martins foi encontrada por meio do método GOD, como mostra a Tabela 2.

A cada um desses parâmetros é atribuído um valor nos limites de 0 e 1 (Tabela 3 ) cujo índice qualitativo é obtido multiplicando os três valores, indicando o grau de vulnerabilidade: nula (insignificante), baixa, média (moderada), alta e extrema (FEITOSA; MANOEL FILHO, 2000).

Conforme indicado na Tabela 4, segundo os autores, são determinadas as classes de vulnerabilidade determinadas pelo método GOD.

Pode-se observar que o índice de vulnerabilidade GOD variou de 0,17 a 0,42 provavelmente devido à repetição dos valores das variáveis, sendo que duas das três variáveis que compõe o método são vinculadas a litologia dos aquíferos. Também produziram três classes de vulnerabilidade, apresentando índices baixos, médios e insignificantes (Figura 23). 
Revista de Geografia (Recife) V. 37, No. 3, 2020

Tabela 2. Índice de vulnerabilidade GOD da bacia endorreica do Tabuleiro do Martins. DISTRIB UIÇÃO DOS POÇOS DA CASAL NA BACIA ENDORREICA TABULEIRO DO MARTINS - MACEIÓ - AL

\begin{tabular}{|c|c|c|c|c|c|c|c|c|c|c|c|}
\hline \multirow{2}{*}{ RE F. } & \multirow{2}{*}{ NOME } & \multicolumn{2}{|c|}{ COORDENADAS } & \multicolumn{2}{|c|}{ Aquífero } & \multicolumn{2}{|c|}{ Litologia } & \multicolumn{2}{|c|}{ Profumdidade } & \multirow[b]{2}{*}{ Indice } & \multirow{2}{*}{$\begin{array}{c}\text { Grau de } \\
\text { Vulnermbilidade }\end{array}$} \\
\hline & & EST E & NORTE & Tipo & G & Tipo & 0 & $\mathrm{NE}(\mathrm{m})$ & D & & \\
\hline 1 & PCIT-01 & 196219 & 8943901 & $\mathrm{~N} / \mathrm{conf}$. (cob.) & 0,60 & Areia e casc. & 0,70 & 33,75 & 0,60 & 0,25 & BAIXO \\
\hline 2 & PCU-01 & 194757 & 8942783 & N/conf. $(c o b)$. & 0,60 & Areia e casc. & 0,70 & 37,50 & 0,60 & 0,25 & B.A.IXO \\
\hline 4 & PGL-02 & 195969 & 8944175 & N/conf.(cob.) & 0,60 & Areia e casc. & 0,70 & 31,00 & 0,60 & 0,25 & BAIXO \\
\hline 5 & PHE-01 & 198931 & 8941445 & N/conf.(cob.) & 0,60 & Areia e casc. & 0,70 & 38,00 & 0,60 & 0,25 & BAIXO \\
\hline 6 & PHE-02 & 198951 & 8941447 & N/conf. & $1, \infty$ & Areia e casc. & 0,70 & 36,15 & 0,60 & 0,42 & MÉDIO \\
\hline 7 & PIN-01A & 194190 & 8943736 & N/conf. $(c o b)$. & 0,60 & Areia e casc. & 0,70 & 42,30 & 0,60 & 0,25 & BAIXXO \\
\hline 8 & PIN-02 & 194109 & 8943668 & N/conf. & $1, \infty$ & Areia e casc. & 0,70 & 39,75 & 0,60 & 0,42 & MÉDIO \\
\hline 9 & PJDL_01A & 198039 & 8941261 & N/conf. & $1, \infty$ & Arein e casc. & 0,70 & 28,80 & 0,60 & 0,42 & MÉDIO \\
\hline 10 & PJDL-02A & 198273 & 8941211 & N/conf.(cob.) & 0,60 & Areia e casc. & 0,70 & 34,28 & 0,60 & 0,25 & BAIXO \\
\hline 11 & PISL-01A & 197261 & 8939723 & N/conf. & 1,00 & Areia e casc. & 0,70 & 37,45 & 0,60 & 0,42 & MÉDIO \\
\hline 12 & PLSL-02 & 197362 & 8940121 & N/conf. & $1, \infty$ & Areia e casc. & 0,70 & 37,99 & 0,60 & 0,42 & MÉDIO \\
\hline 13 & PLSL-04 & 197427 & 8940582 & N/conf.(cob.) & 0,60 & Areia e casc. & 0,70 & 40,10 & 0,60 & 0,25 & BAIXO \\
\hline 14 & PLSL-05 & 197866 & 8940854 & Niconf. & $1, \infty$ & Areia e casc. & 0,70 & 36,20 & 0,60 & 0,42 & MÉDIO \\
\hline 15 & PNSA.-01 & 197419 & 8940877 & N/conf. & $1, \infty$ & Areia e casc. & 0,70 & 37,00 & 0,60 & 0,42 & MÉDIO \\
\hline 16 & POL-01 & 195081 & 8940108 & N/conf.(cob.) & 0,60 & Areia e casc. & 0,70 & 37,90 & 0,60 & 0,25 & B.AIXO \\
\hline 17 & POL-02 & 195105 & 8940095 & $\mathrm{~N} / \mathrm{conf} .(\mathrm{cob})$. & 0,60 & Areia e casc. & 0,70 & 38,97 & 0,60 & 0,25 & B.AIXO \\
\hline 18 & POL-03 & 195340 & 8939743 & N/conf. & 1,00 & Areia e casc. & 0,70 & 46,00 & 0,60 & 0,42 & MÉDIO \\
\hline 19 & PPG-01 & 198659 & 8941421 & N/conf.(cob.) & 0,60 & Areia e casc. & 0,70 & 36,72 & 0,60 & 0,25 & BAIXO \\
\hline 20 & PSH-01 & 196060 & 8943818 & $\mathrm{~N} / \mathrm{conf}$. (cob.) & 0,60 & Areia $=$ casc. & 0,70 & 31,98 & 0,60 & 0,25 & BAIXO \\
\hline 22 & PSL-02 & 198040 & 8941762 & N/conf.(cob.) & 0,60 & Areia $=$ casc. & 0,70 & 18,72 & 0,80 & 0,34 & MÉDIO \\
\hline 23 & PSL-03 & 198418 & 8941708 & N/conf. & $1, \infty$ & Areia e casc. & 0,70 & 28,00 & 0,60 & 0,42 & MÉDIO \\
\hline 24 & PT-01 & 195725 & 8940887 & $\mathrm{~N} / \mathrm{conf} \cdot(\mathrm{cob})$. & 0,60 & Areia e casc. & 0,70 & 31,46 & 0,60 & 0,25 & BA.IXO \\
\hline 25 & PT-03 & 196395 & 8941001 & N/conf. & $1, \infty$ & Areia e casc. & 0,70 & 22,10 & 0,60 & 0,42 & MÉDIO \\
\hline 26 & PT-04 & 195626 & 8940818 & N/conf.(cob.) & 0,60 & Areia e casc. & 0,70 & 39,18 & 0,60 & 0,25 & BAIXO \\
\hline 27 & PT-05 & 196476 & 8940882 & N/conf.(cob.) & 0,60 & Areia e casc. & 0,70 & 14,20 & 0,80 & 0,34 & MÉDIO \\
\hline 28 & PT-06 & 195795 & 8940036 & N/conf. & $1, \infty$ & Arein e casc. & 0,70 & 40,29 & 0,60 & 0,42 & MÉDIO \\
\hline 29 & PT-07 & 195529 & 8939760 & N/conf. & $1, \infty$ & Areia e casc. & 0,70 & 49,36 & 0,60 & 0,42 & MÉDIO \\
\hline 30 & PEGM-01 & 193607 & 8944203 & $\mathrm{~N} / \mathrm{conf}$ (cob.) & 0,60 & Areia $=$ casc. & 0,70 & 50,13 & 0,40 & 0,17 & BAIXO \\
\hline 31 & $\mathrm{PCB}$ 05 & 193912 & 8941565 & $\mathrm{~N} / \mathrm{conf}$. (cob.) & 0,60 & Areia e casc. & 0,70 & 66,68 & 0,40 & 0,17 & BAIXO \\
\hline 32 & PCB 06 & 194008 & 8941812 & $N / \operatorname{conf}$. & $1, \infty$ & Areia $=\operatorname{cas} c$. & 0,70 & 64,30 & 0,40 & 0,28 & BAIXO \\
\hline 33 & $\mathrm{PHV} 03$ & 192688 & 8944747 & N/conf.(cob.) & 0,60 & Areia e casc. & 0,70 & 42,26 & 0,60 & 0,25 & BAIXO \\
\hline 34 & PMM O2 & 192182 & 8945061 & Conf. & 0,20 & Areia e casc. & 0,70 & 45,00 & 0,60 & 0,08 & MVSIGNIFICANTE \\
\hline 35 & PMM O3 & 192168 & 8945173 & Conf & 0,60 & Areia $e \operatorname{cas} c$. & 0,70 & 56,20 & 0,40 & 0,17 & BAIXO \\
\hline 36 & PMLAI 01 & 198578 & 8936483 & $\mathrm{~N} / \operatorname{conf}$. (cob.) & 0,60 & Areia e cas $\mathrm{C}$. & 0,70 & 43,70 & 0,60 & 0,25 & BAIXO \\
\hline 37 & PMLAI 02 & 198527 & $\$ 936667$ & $\mathrm{~N} / \mathrm{conf}$.(cob.) & 0,60 & Areia e casc. & 0,70 & 49,00 & 0,60 & 0,25 & BAIXO \\
\hline 38 & PC J 03 & 198754 & 8936309 & $\mathrm{~N} / \operatorname{conf} .(\mathrm{cob})$. & 0,60 & Areia e casc. & 0,70 & 41,00 & 0,60 & 0,25 & B.AIXO \\
\hline 39 & PCJS 02 & 196890 & 8937059 & N/conf.(cob.) & 0,60 & Areia e casc. & 0,70 & 50,00 & 0,60 & 0,25 & B.A.IXO \\
\hline
\end{tabular}

Fonte: Elaborado pelo autor (2019)

Tabela 3. Vulnerabilidade do aquífero a contaminação

\begin{tabular}{c|c|c|c|c}
\hline Insignificante & Baixa & Média & Alta & Extrema \\
\hline $0-0,1$ & $0,1-0,3$ & $0,3-0,5$ & $0,5-0,7$ & $0,7-1,0$ \\
\hline
\end{tabular}

Fonte: Foster et al. (2006)

Tabela 4. Definições das classes de vulnerabilidade de um aquífero à contaminação

\begin{tabular}{c|l}
\hline Classes de vulnerabilidade & \multicolumn{1}{|c}{ Definição correspondente } \\
\hline Insignificante & $\begin{array}{l}\text { Não ocorre aquífero, pela ausência de água em quantidade } \\
\text { significante, pela baixa qualidade natural. }\end{array}$ \\
\hline Baixa & $\begin{array}{l}\text { Vulnerável somente aos poluentes conservadores } \\
\text { em longo prazo, quando descarregado ou lixiviado continuamente. }\end{array}$ \\
\hline Média & $\begin{array}{l}\text { Vulnerável a alguns contaminantes, mas somente quando } \\
\text { descarregado continuamente ou lixiviado (sais, nitratos e alguns } \\
\text { solventes organo-sintéticos). }\end{array}$ \\
\hline Extrema & $\begin{array}{l}\text { Vulnerável a muitos contaminantes (excetos aqueles fortemente } \\
\text { adsorvidos ou facilmente transformados) em muitos cenários de } \\
\text { contaminação. }\end{array}$ \\
\hline $\begin{array}{l}\text { Vulnerável à maioria dos contaminantes da água com rápido } \\
\text { impacto em muitos cenários de poluição (sensibilidade para } \\
\text { contaminantes degradáveis, como bactérias e vírus). }\end{array}$ \\
\hline
\end{tabular}

Fonte: Foster et al. (2006) 


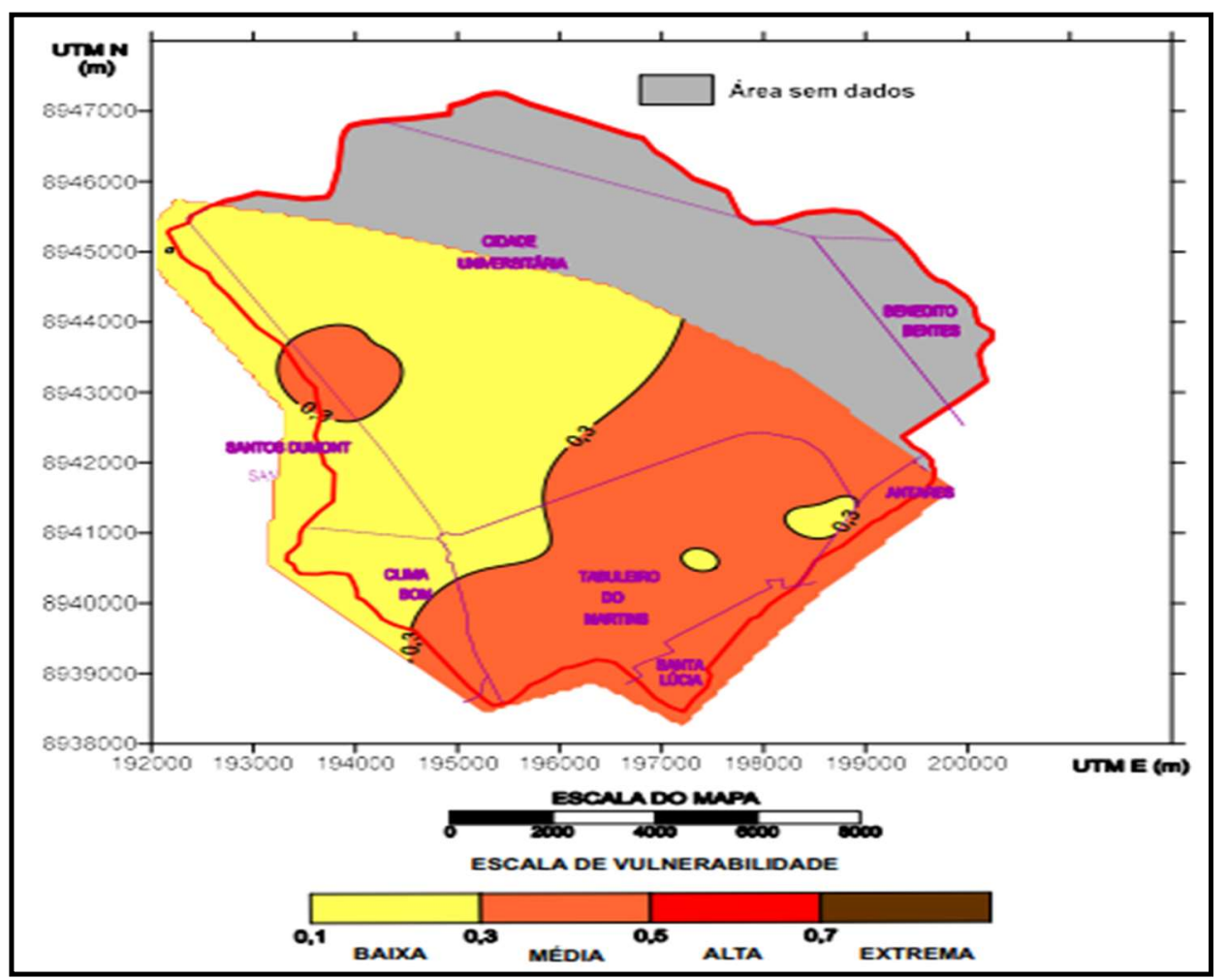

Figura 23. Vulnerabilidade à contaminação da bacia endorreica do Tabuleiro do Martins Fonte: Elaborado pelo autor (2019)

\section{CONSIDERAÇÕES FINAIS}

Os estudos realizados permitiram inferir que o sistema de esgotamento sanitário da região, utilizando fossas sépticas individuais e condominiais, juntamente com sumidouros, pode ser responsável pelas anomalias registradas em diversos parâmetros físico-químicos das águas subterrâneas locais, com base nos resultados das análises das águas coletadas nos poços da CASAL.

As características geológicas locais imprimem nas águas subterrâneas uma acidez elevada, comprovada pelos baixos valores do $\mathrm{pH}$.

As informações constantes nas análises da qualidade da água realizadas pela CASAL permitiram a análise estatística dos diversos parâmetros físicos e químicos da água, possibilitando avaliar a qualidade das águas comparando com os padrões de potabilidade estabelecidos conforme a legislação, como também comparar os resultados nos dois períodos (2008 e 2018) para avaliação da evolução temporal da qualidade das águas subterrâneas locais.

A partir dos resultados gerados nota-se que a metodologia GOD indicou o potencial de vulnerabilidade natural à contaminação da bacia endorreica do Tabuleiro do Martins. Os resultados mostram que a bacia apresenta vulnerabilidade baixa a moderada. Contudo, a 
presença de atividades potencialmente contaminantes não é considerada pelo método GOD, as quais aumentam o risco de poluição ambiental do sistema estudado.

Destacaram-se com comprometimento da qualidade das águas, os parâmetros: $\mathrm{pH}$, cor aparente, turbidez, condutância específica, acidez, alcalinidade, magnésio, cloreto, amônia, nitrato, ferro total e $\mathrm{CO}_{2}$.

No ano de 2008 o poço PT-01 (poço Tabuleiro), apresentou amônia de 1,92mg/L. Já no ano de 2018, o poço PCB-05 (poço Clima Bom), para o mesmo parâmetro, expôs 0,9mg/L, valores que caracterizam contaminação.

Os dados analisados do nitrato no ano de 2018 são preocupantes por apresentarem nove poços (PHE-01, PIN-02, PLSL-02, PCB-05, PCB-06, PMAL-01, PMAL-02, PCJ-03 e PCJS-02) ultrapassando teores acima de $5 \mathrm{mg} / \mathrm{L}$, principal indicador de contaminação por esgoto;

Os resultados ora apresentados são indicativos de que já há comprometimento da qualidade das águas subterrâneas na região do Tabuleiro do Martins, identificando áreas onde os diversos parâmetros estudados mostram valores fora do padrão de potabilidade, como os bairros do Santos Dumont, Clima Bom, Cidade Universitária, Tabuleiro do Martins e Santa Lúcia, considerando que essas águas têm como uso preponderante o abastecimento humano através da captação por poços tubulares e distribuição da água pela CASAL para a população de grande parte da cidade de Maceió.

\section{AGRADECIMENTOS}

À Fundação de Amparo à Pesquisa do Estado de Alagoas (FAPEAL) pala concessão de bolsa de mestrado para a realização do projeto de pesquisa.

\section{REFERÊNCIAS}

ALABURDA, Janete; NISHIHARA, Linda. Presença de compostos de nitrogênio em águas de poços. Revista de Saúde Pública, São Paulo, v. 32, n.32, p. 161, abril. 1998.

BRASIL. Portaria do Ministério da Saúde no 36, de 19 de janeiro de 1990. Dispõe sobre potabilidade da água destinada ao consumo humano, a serem observadas em todo o território nacional. Brasília, DF, 1990. 
BRASIL. Portaria do Ministério da Saúde no 2914, de 12 de dezembro de 2011. Dispõe sobre os procedimentos de controle e vigilância da qualidade da água para o consumo humano e seu padrão de potabilidade. Brasília, DF, 2011 b.

BRASIL. Resolução Conama $\mathbf{n}^{\circ}$ 335, de 03 de abril de 2003. Dispõe sobre as condições e padrões de lançamento de efluentes, complementa e altera a Resolução n 368/06. Disponível em: < http:// http://www2.mma.gov.br/port/conama/legiabre.cfm?codlegi=359> Acesso em: 17 de agosto de 2020.

COMPANHIA DE TECNOLOGIA DE SANEAMENTO AMBIENTAL - CETESB., 1996. Métodos simplificados para análises bacteriológicas de água / Petra S. Sanchez. São Paulo. $67 \mathrm{p}$.

ESPINDULA, C. J. Caracterização bacteriológica e físico-química das águas do aquífero freático do cemitério da Várzea - Recife. 2004. 131f. Dissertação (Mestrado em Geociências) - Centro de Tecnologia e Geociências, Universidade Federal de Pernambuco, Recife, 2004.

FEITOSA, F. A. C.; MANOEL FILHO, J. Hidrogeologia: Conceitos e Aplicações. Fortaleza: CPRM, LABHID - UFPE, ed. 2, 391 p., 2000.

FOSTER, S. S. D.; HIRATA, R. C. A. Groundwater pollution risk evaluation: the methodology using available data. Lima: CEPIS/PAHO/WHO, 1988.

FOSTER, S.; HIRATA, R.; GOMES, D.; D'ELIA, M.; PARIS, M. Proteção da qualidade da água subterrânea: um guia para empresas de abastecimento de água, órgãos municipais e agências ambientais. São Paulo: Servemar, 2006.

GLEICK, P. H. The world's water. 2000-2001. Report on Freshwater Resources. Island Press, 2000. 315p.

MACEIÓ, Prefeitura Municipal de. Lei $n^{\circ}$ 4.952, de 06/01/2000. Disponível em: $<$ http://www.maceio.al.gov.br/wp-content/uploads/lucasragucci/pdf/2016/01/14-Lei

Municipal-5.118-de-2000-Altera-lei-Municipal-4575-de-1996.pdf $>$ Acesso em: 17 agosto de 2020 .

MORAIS, R.M.O. Estudo faciológico da Formação Barreiras na região entre Marica e Barra de Itabapoana, estado do Rio de Janeiro. Dissertação (Mestrado em Geologia) Instituto de Geociências, Universidade Federal do Rio de Janeiro. 113 p. 2001. 
MORAIS, R.M.O.; MELLO, C.L.; COSTA, F.O.; SANTOS, P.F. Fácies sedimentares e ambientes deposicionais associados aos depósitos da Formação Barreiras no estado do Rio de Janeiro. Geologia USP (Série Científica), v. 6, n. 2, p. 19-30, 2006.

PEPLAU, Guilherme Rocha. Influência da Variação da Urbanização nas Vazões de Drenagem na Bacia do Rio Jacarecica em Maceió-AL. Dissertação de Mestrado. Recife, 2005.

ROGERS, P. P. Water governance, water security and water sustainability. In: ROGERS, P. P. et al. (Ed.) Water crisis: myth or reality? London: Fundación Marcelino Botín, Taylor \& Francis, 2006. p.3-36.

SOMLYODY, L; VARIS, O. Freshwater under pressure. International Review for Environmental Strategies, v.6, n.2, p.181-204, 2006.

TUNDISI, J. G. Água no século XXI: enfrentando a escassez. São Carlos: RiMa, IIE, 2003. $248 p$.

TUNDISI, J. G.; MATSUMURA-TUNDISI, T. Limnologia. São Paulo: Oficina de Textos, 2008. 